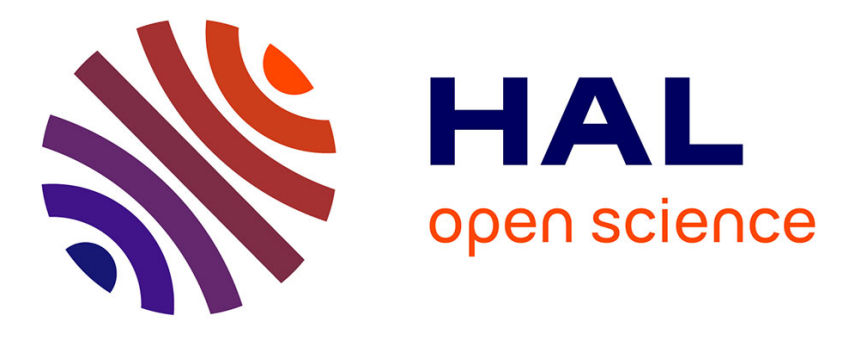

\title{
Advancing Solutions to the Carbohydrate Sequencing Challenge
}

\author{
Christopher Gray, Lukasz Migas, Perdita Barran, Kevin Pagel, Peter \\ Seeberger, Claire Eyers, Geert-Jan Boons, Nicola Pohl, Isabelle Compagnon, \\ Göran Widmalm, et al.
}

\section{To cite this version:}

Christopher Gray, Lukasz Migas, Perdita Barran, Kevin Pagel, Peter Seeberger, et al.. Advancing Solutions to the Carbohydrate Sequencing Challenge. Journal of the American Chemical Society, 2019, 141 (37), pp.14463-14479. 10.1021/jacs.9b06406 . hal-02365096

\section{HAL Id: hal-02365096 https://univ-lyon1.hal.science/hal-02365096}

Submitted on 20 Jan 2021

HAL is a multi-disciplinary open access archive for the deposit and dissemination of scientific research documents, whether they are published or not. The documents may come from teaching and research institutions in France or abroad, or from public or private research centers.
L'archive ouverte pluridisciplinaire HAL, est destinée au dépôt et à la diffusion de documents scientifiques de niveau recherche, publiés ou non, émanant des établissements d'enseignement et de recherche français ou étrangers, des laboratoires publics ou privés. 


\section{Advancing Solutions to the Carbohydrate Sequencing Challenge}

DOI:

10.1021/jacs.9b06406

Document Version

Accepted author manuscript

Link to publication record in Manchester Research Explorer

\section{Citation for published version (APA):}

Gray, C. J., Migas, L. G., Barran, P. E., Pagel, K., Seeberger, P. H., Eyers, C. E., Boons, G., Pohl, N. L. B., Compagnon, I., Widmalm, G., \& Flitsch, S. L. (2019). Advancing Solutions to the Carbohydrate Sequencing Challenge. Journal of the American Chemical Society. https://doi.org/10.1021/jacs.9b06406

\section{Published in:}

Journal of the American Chemical Society

\section{Citing this paper}

Please note that where the full-text provided on Manchester Research Explorer is the Author Accepted Manuscript or Proof version this may differ from the final Published version. If citing, it is advised that you check and use the publisher's definitive version.

\section{General rights}

Copyright and moral rights for the publications made accessible in the Research Explorer are retained by the authors and/or other copyright owners and it is a condition of accessing publications that users recognise and abide by the legal requirements associated with these rights.

\section{Takedown policy}

If you believe that this document breaches copyright please refer to the University of Manchester's Takedown Procedures [http://man.ac.uk/04Y6Bo] or contact uml.scholarlycommunications@manchester.ac.uk providing relevant details, so we can investigate your claim.

\section{OPEN ACCESS}




\title{
Advancing Solutions to the Carbohydrate Sequencing Challenge
}

\author{
Christopher J. Gray, ${ }^{1}$ Lukasz G, Migas, ${ }^{1}$ Perdita E. Barran, ${ }^{1}$ Kevin Pagel, ${ }^{2}$ Peter H. Seeberger, ${ }^{3}$ \\ Claire E. Eyers, ${ }^{4}$ Geert-Jan Boons,${ }^{5}$ Nicola L. B. Pohl, ${ }^{6}$ Isabelle Compagnon, ${ }^{7,8}$ Göran Widmalm, ${ }^{9}$ \\ and Sabine L. Flitsch ${ }^{1, *}$
}

1 School of Chemistry \& Manchester Institute of Biotechnology, The University of Manchester, 131 Princess Street, Manchester M1 7DN, UK

\author{
2 Institute for Chemistry and Biochemistry, Freie Universität Berlin, Takustraße 3, 14195 Berlin, Germany \\ 3 Biomolecular Systems Department, Max Planck Institute for Colloids and Interfaces, Am Muehlenberg 1, 14476 Pots- \\ dam, Germany \\ 4 Department of Biochemistry, Institute of Integrative Biology, University of Liverpool, Crown Street, Liverpool, L69 \\ $7 \mathrm{ZB}, \mathrm{UK}$ \\ 5 Complex Carbohydrate Research Center, University of Georgia, Athens, GA, 30602, USA \\ 6 Department of Chemistry, Indiana University, Bloomington, IN 47405, USA \\ 7 Institut Lumière Matière, UMR5306 Université Lyon 1-CNRS; Université de Lyon 69622 Villeurbanne Cedex, France \\ 8 Institut Universitaire de France IUF, 103 Blvd St Michel, 75005 Paris, France \\ 9 Department of Organic Chemistry, Arrhenius Laboratory, Stockholm University, S-106 91 Stockholm, Sweden
}

KEYWORDS: Glycan, Carbohydrate, NMR, mass spectrometry, liquid chromatography, ion-mobility spectrometry, infrared spectroscopy

\begin{abstract}
Carbohydrates possess a variety of distinct features with stereochemistry playing a particularly important role in distinguishing their structure and function. Monosaccharide building blocks are defined by a high density of chiral centers. Additionally, the anomericity and regio-chemistry of the glycosidic linkages carry important biological information. Any carbohydrate-sequencing method needs to be precise in determining all aspects of this stereo-diversity. Recently, several advances have been made in developing fast and precise analytical techniques that have the potential to address the stereochemical complexity of carbohydrates. This perspective seeks to provide an overview of some of these emerging techniques, focusing on those that are based on NMR and MS-hybridized technologies including ion mobility spectrometry and IR spectroscopy.
\end{abstract}

\section{Introduction}

Intricately fine-tuned glycans decorate all cells and have a plethora of functions ranging from mediating cell-cell adhesion, cell motility, protein folding and immune response. ${ }^{1,2}$ Their functions are mediated either by recognition with a glycan-binding protein (GBP) or through the inherent chemical properties of the saccharide including altering the properties of any conjugate that they are bound to. ${ }^{1}$ Natural glycans are typically heterogeneous with the abundances of these different glycoforms varying over time, from individual-to-individual, nutritional state, from the cell environment, along with many other factors that are still poorly understood. ${ }^{3,4}$ These glycans are exploited during pathogenesis and aberrant glycan structures are associated with a number of disease states. ${ }^{5}$ Glycoforms may also change during the course of disease progression, so identifying these changes enables early treatment and treatment stratification. ${ }^{6}$ Given the established connection between their structure and their function, full characterization of unknown carbohydrates ideally with minimal sample derivatization/labelling, is critical and represents one of the major roadblocks within the progress of the glycosciences. ${ }^{7}$ Furthermore, the development of glycan and glycoconjugate therapeutics will necessitate accurate, precise, sensitive and high-throughput analytics to unequivocally characterize the carbohydrate structure.

Carbohydrates possess unparalleled levels of structural complexity compared to other classes of biological molecules and are found free, adhered to proteins and lipids and as polysaccharides. This complexity normally arises from the number of chemically similar (and often isomeric) monosaccharide building blocks, the position and orientation of glycosidic linkages and branching (Figure 1). The biosynthesis of carbohydrates is not template-driven; although the complex biosynthetic pathways of glycoconjugates have been extensively studied, in particular for human glycans that are all derived from 10 monomeric building blocks and many structures contain conserved cores. As a result, many analytical approaches rely on these studies to infer chemical structures. Where the pathways are less predictable or unknown altogether, such as in plant metabolites or bacterial glycans, analysis is still very slow. Many analytical approaches require highly purified standards (sometimes in amounts greater than biologically available) that are difficult to obtain by isolation or synthesis, necessitate derivatization to facilitate separation 
or detection, and often employ cocktails of glycosidases, which are not available for every linkage. As a result, our understanding of endogenous carbohydrate structure and function still lags behind that of other biomolecules, despite carbohydrates representing the most abundant biological class.

\section{a)}
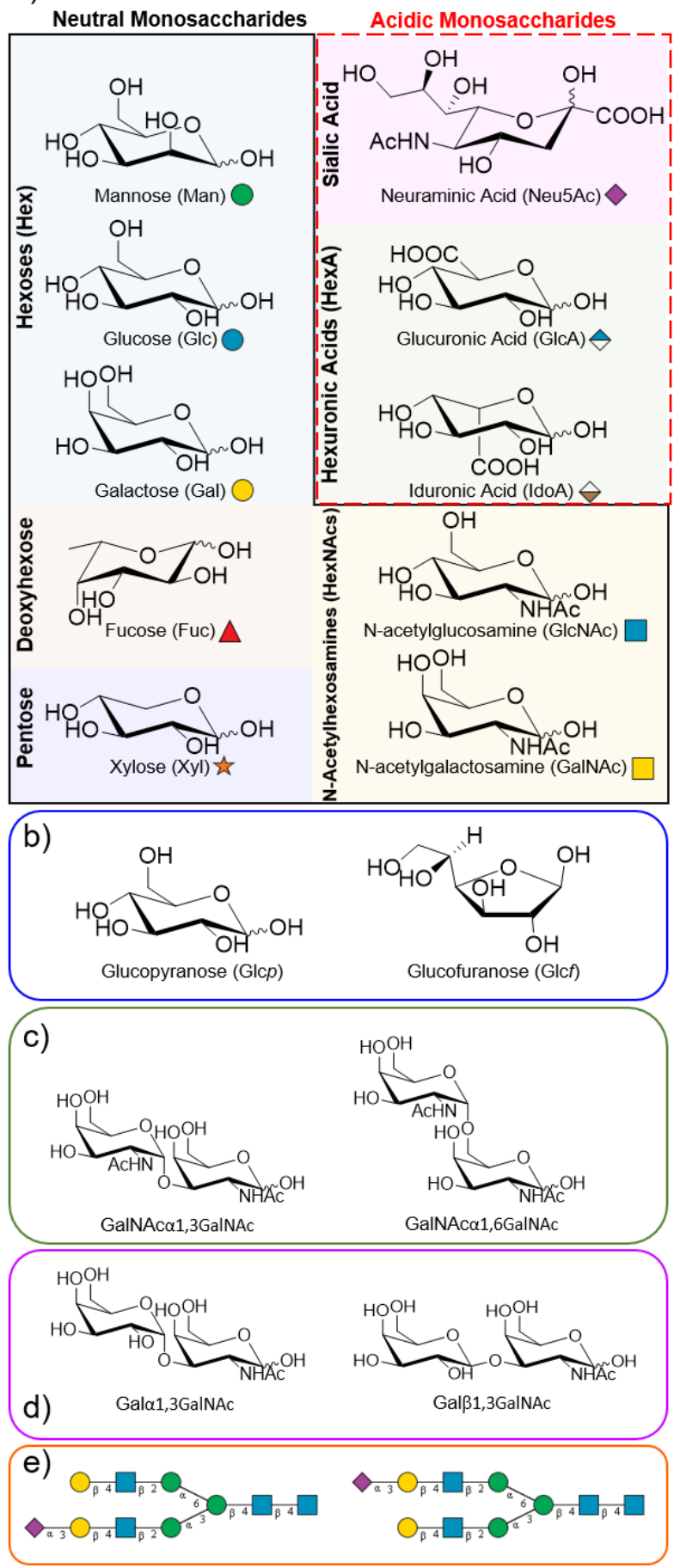

Figure 1. Chemical structures of the ten classical human monosaccharides (and their respective Symbol Nomenclature for Glycans (SNFG) nomenclature, ${ }^{8}$ a). Additional isomerism resulting from ring size (b), regioisomerism (c), anomeric configuration (d) of the glycosidic bond and positional isomerism (e).

Development of technologies to facilitate glycan research has been highlighted as a key area within the scientific community with identification/sequencing being a crucial contributing facet within this program, ${ }^{9}$ given that reliable sequencing techniques are still very slow or not available. This perspective focuses on the challenges associated with glycan analysis and highlights recent promising technologies, in particular, the development of more sensitive NMR methods and the increasing amount of stereochemical information obtained from MS-based gas phase techniques.

\section{A problem of size, linkages, numbers and "shapes"}

Carbohydrates exist in a wide variety of sizes, from simple monosaccharides to large insoluble polysaccharides. The biological information encoded in these glycoconjugates relies significantly on stereoisomerism: common monosaccharide building blocks in human glycans such as glucose, galactose, and mannose differ from each other by inversion of just a single stereocenter (Figure 1a), yet each isomer has distinctly different biological roles and properties. This chemical similarity between the building blocks makes their separation and characterization challenging, especially for techniques like mass spectrometry (MS) that rely on mass differences. Oligosaccharides may also be altered enzymatically with functionality such as sulfation, acetylation, and phosphorylation, thereby further complicating analyses. In addition to the individual building blocks, isomerism of glycosidic linkages also needs to be defined. Monosaccharides can be linked by glycosidic bonds at multiple positions (including branching from the same residue) allowing for the formation of linkage regioisomers. The inherent chirality of the anomeric carbon adds $\alpha$ - and $\beta$ - stereoisomerism. Finally, the monosaccharides can exist as 6-membered rings, pyranose $(p)$, or 5-membered rings, furanose $(f)$ (Figure 1). Bacteria also contain a much more diverse range of monosaccharide building blocks compared to the 10 human ones, many of which remain uncharacterized.

Seemingly, carbohydrates are perfectly evolved biomolecules to contain the maximum amount of structural information within the least amount of atomic space; it is perhaps unsurprising that they mediate such a great number of diverse biological processes. The incredibly large numbers of possible permutations, ${ }^{10}$ range of monosaccharide building blocks and the size range of the glycans make finding a single analytical approach capable of unambiguously discerning all stereochemical information highly challenging. This is reflected within the glycobiology/chemistry community where multiple analytical techniques are normally combined. Fortunately for researchers, biological pathways limit the number of species actually observed to a cohort of common structural motifs. This knowledge has been exploited in the analysis of complex mixtures of animal $\mathrm{N}$-glycans, carbohydrates that are commonly found to be linked to asparagine residues in proteins within a defined consensus sequence $\mathrm{N}-\mathrm{X}-\mathrm{S} / \mathrm{T}$, whose biosynthetic pathways and resulting structures are relatively well known. Also, these assemblies all expand from a core Man3 pentasaccharide structure. These $N$-glycans can now be profiled even in a high-throughput manner. ${ }^{6,11-15}$ Although very important for modern biotechnology, $N$-glycan and to some extent $O$-glycan analysis remains a highly specialized field which is not applicable to many other glycoconjugates, the structures of which remain difficult to elucidate. For example, there has been recent growth in bacterial glycomics since their discovery. However, much of the field is limited as the biological glycosylation pathways are not fully understood and they contain a much larger pool of diverse 
monosaccharide building blocks compared to human systems. ${ }^{16}$ As a result, many glycan structures are unknown or only partially known. Complete structure elucidation is extremely challenging with current analytical approaches, therefore most effort in the area focusses on characterizing the enzymatic pathways as a means to characterize structures. ${ }^{16}$ Although, this assumes pathways are highly conserved which may not be the case.

\section{Structure elucidation: analytical approaches}

Often combinations of a diverse variety of methodologies and analytical techniques have been used to elucidate structural information of glycans and their conjugates. These include (micro)arrays, liquid chromatography (LC), capillary electrophoresis (CE), nuclear magnetic resonance (NMR) and MS. These approaches usually offer different levels of structural information and often incomplete pictures of the glycans being studied. Figure 2 presents an overview of sample-preparation methods and analytical methods that are often combined in different workflows. Classically, glycans are tagged at their reducing terminus with a fluorescent tag and analyzed by (U/)HPLC. The retention times can be standardized to a refence ladder (glucose units, GU) and these GU compared to a standard library of known glycans. This provides non-direct structural information. MS and MS/MS may be combined with LC to provide an alternative detection technique enabling compositions to be discerned directly, with MS/MS potentially also providing connectivity information. Specific glycosidases can be employed to selectively trim the ends of glycan branches providing indirect structural information. Glycan samples can be perderivatized to improve retention, deduce regiochemistry from MS/MS spectra and improve ionization amongst other benefits. Either way, MS(/MS) is typically blind to stereochemical information. Alternatively, complex glycans can be completely hydrolyzed to their monosaccharide components (also potentially combined with prior perderivatization to facilitate regiochemical assignments) and retention of these units compared to monosaccharide libraries. This provides information on the composition of monosaccharides present, but will lose much connectivity information. Alternatively, glycans can be directly analyzed by NMR, which can provide a full complement of structural information although this frequently requires greater than biological amounts of samples, is time consuming and can still miss information especially with no prior knowledge of the sample structure. Overall, there is no consensus approach to identify a glycan and most approaches are dictated by the glycan "family" (e.g. N/O-glycans, polysaccharides, glycolipids, etc.). As a result, multiple strategies are often used in the same glycomics experiment, improving confidence in structural assignments. Some of the more prominent techniques with a special focus on more recent hybridized-MS approaches, are sub-sectioned below and the structural information that can be obtained discussed in greater detail. It should be noted that the use of LC and arraybased technologies and lectins will not be discussed in great detail here as they have been recently extensively reviewed in their own right. ${ }^{17-22}(\mathrm{U} /)$ HPLC have been at the forefront of analytical techniques used to separate, isolate and, when standards are available, characterize carbohydrates. Typically, reducing-end tagged glycans retention times are converted to "glucose units" (GU) in reference to the dextran standard, reducing day-to-day or system variations. ${ }^{23,} 24$ These GU can then be compared to reference libraries. Monitoring shifts in GU upon action of specific exoglycosidases provides additional indirect information. ${ }^{11}$ Even though LC does not provide direct structural information, these methods have been incredibly important for the glycomics community, especially $\mathrm{N}$-glycans. ${ }^{6,23-25}$ Certainly, any strategy that seeks de novo identification of the complex sequences within carbohydrates will undoubtedly need pre-separation of complex biological material prior to reproducible analyses.

Classically, arraying extensive libraries of glycans and screening them with fluorescently-tagged lectins whose binding motifs have been characterized can generate vast amounts of structural information rapidly. These experiments can suggest the presence of certain motifs within the arrayed glycans that can be collaborated in conjunction with exoglycosidases treatment (i.e. is binding lost to a certain motif after a glycan has been treated with specific exoglycosidase(s)). These approaches do not always provide direct fine structural information and promiscuity in lectin binding can lead to possible false assignments. Also, exoglycosidases do not exist for every natural glycosidic linkage. They can also be challenging for identifying unusual glycans that may be encountered in bacterial or plant analysis. Similarly, enrichment of targeted glycans with lectin affinity methods downstream of other technologies provides clues on motifs present, which can increase the confidence in identification upstream.

\section{Mass Spectrometry}

Over the past few decades, advancements in MS instrumentation including detectors, dissociation techniques and mass analyzers have seen application of MS within the glycomics community increase significantly. Low amounts of glycans can be analyzed rapidly (fmol), sometimes with extraordinary levels of resolving power. Combined with knowledge of biological pathways, MS profiles of glycans facilitate rapid characterization of the structural "families" (possible isomers still complicate elucidation by MS alone), potentially in a quantitative manner. Tandem mass spectrometry (MS/MS) is particularly useful to dissociate glycans into smaller fragments that can reveal structural motifs directly. Glycans dissociate either across the glycosidic bond (forming $\mathrm{B}-, \mathrm{Z}-, \mathrm{C}$ - and $\mathrm{Y}$-ions), or across the monosaccharide ring (Aand $\mathrm{X}$-ions) (Figure 3). ${ }^{26}$ Glycosidic dissociation pathways typically reveal broad sequence and composition information, whereas cross-ring dissociation can reveal regiochemical information. ${ }^{27}$ Usually, neither type of product ion are diagnostic for anomeric differences or lead to stereochemical assignment of the monosaccharide building block. Commercial instrumentation exists in a variety of different 'layouts' of ionization techniques, dissociation methods and mass analyzers. As a result, instrumentation that manipulates glycan ions can be chosen that best suits an experimental pathway required.

Oligosaccharides typically vary from being neutral to highly acidic and therefore are studied as both positively and negatively charged species. The nature of the adduct formed upon ionization can be influenced by doping with salts (sodium, lithium, nitrate etc.). Any attached conjugates or derivatization also influences the preferred adduct (e.g. glycopeptides readily protonate). Consequently, there is significant variation in ionization efficiency between oligosaccharides that can make quantification challenging for MS, although addressable. For example, permethylation can be used to sequester these differentially ionizable groups, thereby minimizing this variation and improving ionization efficiency 


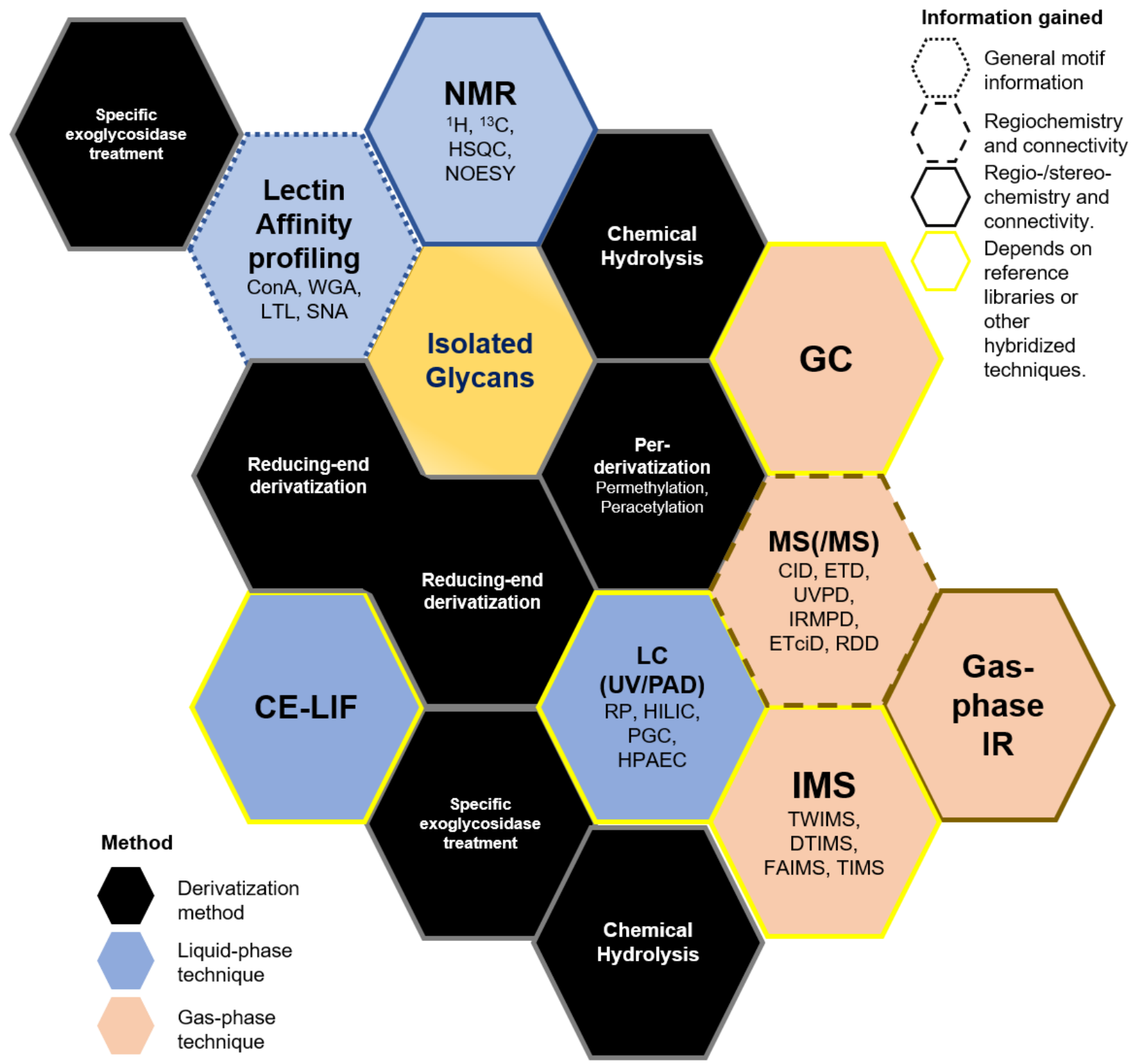

Figure 2. Overview of the analytical techniques and some common sample preparation steps to analyze isolated glycans (and glycoconjugates). Adjoining hexagon tiles indicate that these techniques may be combined, although for clarity, not every single combination is included (such as direct MS/MS or direct LC of isolated glycans). Black hexagons are sample preparation steps. Blue hexagons are solution-phase and orange hexagons are gas-phase analytical techniques. Hexagons with dotted outlines typically provide general glycan motif information with no precise atomistic information; dashed outlines typically provide regiochemistry and connectivity but not stereochemistry; solid outlines can provide the full complement of connectivity, regiochemistry and stereochemistry. Analytical techniques with a solid yellow outline may be used as a separation technique in combination with other approaches and/or used as a diagnostic tool where the separation time under a standardized set of conditions and instrumentation can be compared to databases of known standards. Therefore, structural information they provide depends on the availability and quality of known standards. Interpretation can also be facilitated by knowledge of biosynthetic pathways of the glycan system being studied.

and therefore sensitivity. ${ }^{28}$ Permethylation also facilitates identification of branching patterns and stabilizes labile sialic acids that often dissociate during matrix-assisted laser desorption/ionization (MALDI) because of ion heating An alternative inventive strategy for sialic acid stabilization was found by selective chemical reaction of the $\alpha 2,3$ and $\alpha 2,6$ regioisomers carboxylate generating a $\mathrm{m} / \mathrm{z}$ shift. ${ }^{29}$

Electrospray ionization (ESI) can readily be coupled to chromatographic separation as they both deal with solution-phase samples; the timescales of MS and LC complement one another being of the order of $\mu$ s and s respectively.
LC facilitates separation (and purification) of the heterogeneous glycan mixtures prior to MS. This reduces signal suppression of analytes by salts, other additives and importantly other analytes. Spectra then consist of fewer ions making analysis simpler and consequently reducing the likelihood of incorrect sequencing. An especially prominent example for glycans is the separation of isomeric forms that are indistinguishable by MS alone. ${ }^{30}$ Without LC separation, any MS/MS spectra will be chimeric and will likely lead to misidentification or will miss important information. As a result, coupling LC and MS is highly beneficial for glycan analysis. A great advantage of using gas phase-based methods for structural analysis is the 
opportunity to dissociate large complex structures to more tangible fragments that are amenable to analysis by $\mathrm{MS}$. Numerous dissociation techniques have been employed in an attempt to maximize the amount of structural information that can be garnered. Collision-induced dissociation (CID) is by far the most prominent technique, ${ }^{25,31-37}$ but electron-based dissociation techniques (electron capture dissociation, ECD; electron detachment dissociation, EDD; electron transfer dissociation, ETD etc.), ${ }^{38-42}$ infrared multiple photon dissociation (IRMPD) ${ }^{43}$ ultraviolet photodissociation (UVPD) ${ }^{44}$ and high-energy CID (HCD) ${ }^{45}$ have also been examined as well as combinatorial strategies like radical-directed dissociation (RDD, combines UVPD and CID), ${ }^{46}$ ETciD and EThcD.$^{47}$ The choice of technique greatly affects the fragmentation pathways and thus information gained. As a generalization, CID and IRMPD often lead to fragmentation of the more labile bonds, which are normally glycosidic linkages, whereas the high-energy CID, electron-based dissociation and UVPD lead to greater cross-ring fragmentation (Figure 3). ${ }^{43,46} \mathrm{Com}-$ binatorial fragmentation approaches such as ETciD, EThcD and RDD typically display advantages between the two complementary techniques. ${ }^{46}$ In reality, the dissociation pathways and resulting fragment ions are influenced by numerous factors, many associated with the analyte ion in question, namely the chemistry of the glycan and its conjugate, neutralist charge state, ${ }^{38,39}$ any adduct ${ }^{43}, 48$ and any derivatization. Glycosidic linkages of sialic acids that decorate the termini of many glycans, readily break by CID (and in-source dissociation) generating little useful information. Similarly, loss of other modifications such as sulfation and phosphorylation tend to be the most favorable pathways and make identifying the residues and positions they modify challenging. Glycans can be chemically derivatized to stabilize some of these groups. ${ }^{49}$ When dealing with glycopeptides, CID favorably breaks apart the glycan first, whereas the peptide portion remains primarily intact. As a result, the site of glycosylation within the peptide sequence can be difficult to identify. In comparison, electron-based dissociation methods preferentially fragment the peptide backbone over the neutral glycan. ${ }^{50}$ Combining these strategies generates complementary information, increasing the confidence and level of structure assignment. Mass spectra are sensitive to differences in precursor structure such that diagnostic product ions can be generated even from isomeric precursors. ${ }^{25,51-55}$ Ashwood et al. recently developed a workflow that resulted in product ions diagnostic for sialylation linkage ( $\alpha 2,3$ versus $\alpha 2,6)$ and arm position for native reduced $\mathrm{N}$ - and $\mathrm{O}$-glycans. ${ }^{54}$ Additionally, the ratio of certain fragment ions will likely differ between isomers, facilitating differentiation. ${ }^{56,57} \mathrm{In}$ fact, Pett et al. recently discovered that the intensities of specific product ions generated by HCD of glycopeptides differed between $\alpha 2,3$ versus $\alpha 2,6$-linked sialic acids. ${ }^{57}$ Because of the number of factors that dictate how carbohydrates fragment, the pathways and thus spectra are difficult to predict $a$ priori and, due to the numerous different fragment ions generated (many of which are isomeric or isobaric), interpretation of glycan MS/MS spectra are often difficult. Also, precise knowledge of the structures formed after dissociation are not well understood although several groups have postulated structures. ${ }^{37,48}$, 53,58 Computational tools capable of interpreting tandem mass spectra lag behind those developed e.g. for proteomics, and are still being developed and improved..$^{59,60}$

Caution must be taken when interpreting MS/MS of underivatized carbohydrates as fucose and sialic acid residues have been observed to 'rearrange' to different positions during $\mathrm{CID} / \mathrm{HCD},{ }^{61}$ significantly increasing the likelihood of false identification. However, these rearrangement reactions do not occur for per-derivatized glycans and seems to be reduced by studying metal adducts compared to protonated species. Recently, evidence has been presented that these rearrangements may occur during MS analysis in the absence of significant activation, so sample preparation and instrumentation conditions need to be carefully selected to minimize these unwanted rearrangements. ${ }^{62}$ As the variety of glycans analyzed increases, undoubtedly more such positional rearrangements will be found for other monosaccharides to complicate analytical work flows.

A major restriction of MS is typically 'blindness' to isomerism. Although recently, in situ additives have been discovered that can be used to discern any aldo- or ketohexose or pentose-including its enantiomeric form-using only MS. ${ }^{63,}{ }^{64} \mathrm{As}$ discussed, MS/MS can be sensitive to isomeric differences especially positional and regio- isomerism, although it is less sensitive to stereochemical variations. MS/MS thus usually only reveals snippets of structural information. As a result, alternative analytical techniques that produce complementary information are still being investigated. Nonetheless, these 'snippets' of MS/MS derived structural information may still be highly valuable, especially to restrict potential candidates and thus facilitates identification when used in combination with other analytical techniques such as NMR spectroscopy.

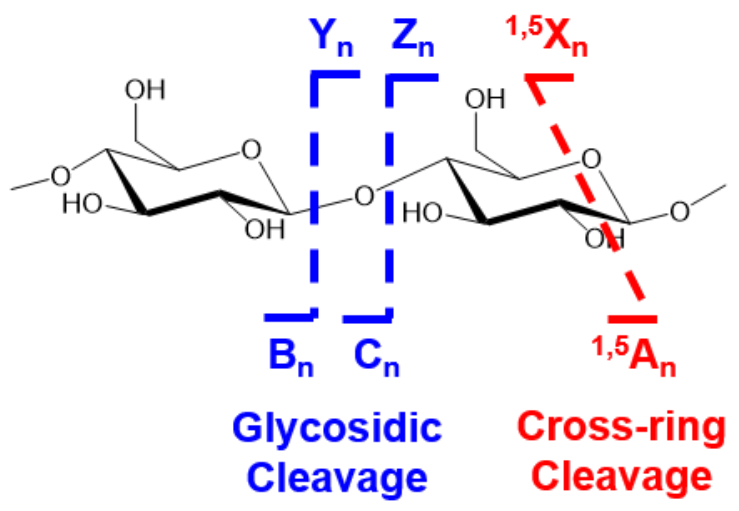

Figure 3. Domon-Costello nomenclature for common fragments generated by gas-phase dissociation techniques. ${ }^{26}$

\section{Ion Mobility Mass Spectrometry (IM-MS)}

Over the last decade, investigations into the applications of ion-mobility spectrometry (IMS) for glycan analysis have increased. ${ }^{65,66}$ Much of this derives from the commercialization of instrumentation that increased its availability compared to early experiments that used "home-built" IMS instrumentation. Most IMS techniques separate ions based on their mobility through an inert drift gas under the influence of a weak electric field. This mobility can be converted to a rotationally averaged collision cross section (CCS, $\Omega$ ) that is an intrinsic property of that ion under the experimental conditions used. Importantly, these CCS values may differ based on the conformation of the glycan analyte, possibly enabling separation of isomers. As a result, IMS is frequently hybridized with MS (IMS timescale ms versus $\mu$ s for MS) readily providing orthogonal information in the same experiment. 

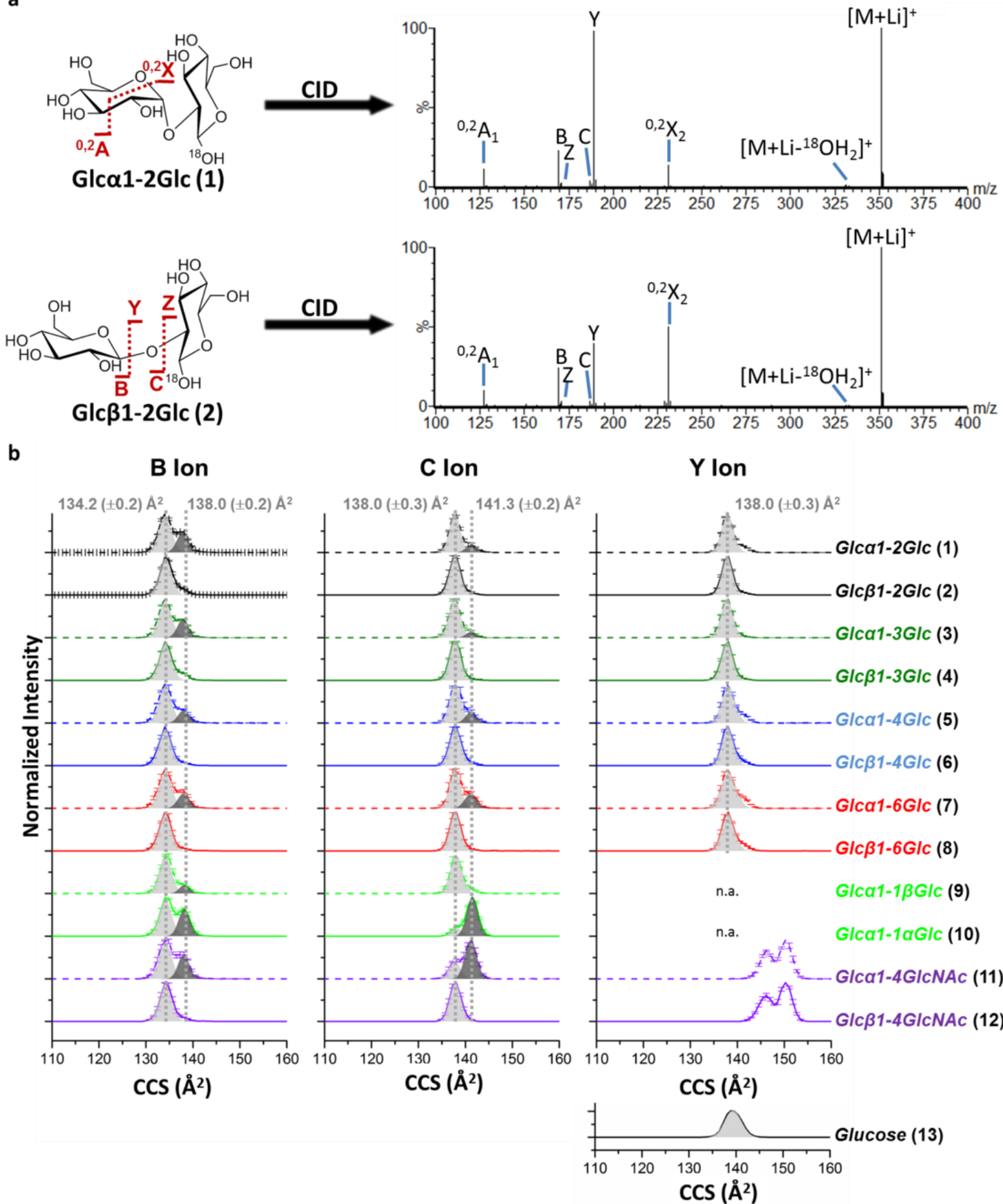

Figure 4. Comparison of tandem mass spectra associated with disaccharide epimers Glc $\alpha 1-2 \mathrm{Glc} \mathbf{1}$ and Glc $\beta 1-2 \mathrm{Glc} 2$ with ion-mobility (IM) arrival time distributions (ATDs) of selected glycosidic product ions. (a) Collision-induced dissociation (CID) of isomeric diglucosides generate similar tandem mass spectra especially for the $\alpha / \beta$-anomers. Disaccharides were selectively ${ }^{18} \mathrm{O}$-labelled at $\mathrm{C} 1$ of the reducing glycan by dissolution in ${ }^{18} \mathrm{O}$-water, allowing mass discrimination of the $\mathrm{C} / \mathrm{Y}$ - and $\mathrm{B} / \mathrm{Z}$-product ion pairs. (b) Ion mobility mass spectrometry generates ATDs associated with B- and C-product ions generated by CID. Significantly, the $\alpha$-glucose terminating precursor display more than one species compared to their $\beta$-glucose counterparts. It is important to note that Domon-Costello nomenclature ${ }^{26}$ for glycosidic product ions does not extend to non-reducing carbohydrates, hence B-and C-ions for 9-10 correspond to $\mathrm{m} / \mathrm{z}, 169$ and 187 respectively despite it being highly likely the C-ion is formed by a Y-ion type mechanism. Displayed ATDs are the sum of three normalized and calibrated replicates. Intensity error bars are shown for all spectra whereas CCS error bars are only displayed for the B-ions of 1-2 for clarity, although the standard deviation is $<0.3 \AA^{2}$ for all shown ATDs. n.a.: not applicable. Reproduced with permission from publisher. ${ }^{53}$ 
Additionally, separation of isomeric glycans prior to MS/MS facilitates identification of these glycoforms that may otherwise be missed or incorrectly assigned. ${ }^{31,35}$ Experimental CCS values can be compared to database values ${ }^{67,68}$ or theoretical computational derived CCSs providing an insight into potential gas-phase conformations. ${ }^{53,69}$ IMS can therefore be used to separate isomeric species and/or to provide structural information. Several different IMS techniques exist such as drift tube IMS (DTIMS), travelling-wave IMS (TWIMS) and field-asymmetric IMS (FAIMS). The details and benefits of these techniques are discussed elsewhere. ${ }^{70} \mathrm{~A}$ multitude of papers have explored separation of isomeric glycans and their conjugates by IMS including structures that differ by regiochemistry, glycosidic bond stereochemistry and monomer stereochemistry. ${ }^{53,69,71-73}$ Because the resolving power of IMS is fairly poor compared to other separation techniques, much effort has been made into methodologies to improve separation, especially since isomeric glycans may only differ by the stereochemistry at a single position, which may not significantly alter the overall conformation. Given that IMS separates ions by their rotationally averaged CCS-to-charge ratio, the charge state, ${ }^{74,75}$ polarity, identity of the adduct, ${ }^{76-78}$ ion-pair coupling ${ }^{79}$ and derivatization ${ }^{80}$ have all been studied. However, there is likely no universal optimal approach to improve IMS separation. Therefore, it is beneficial to systematically test the optimal set of conditions to separate the glycans/glycoconjugates of interest. Improving IMS resolving power by increasing the drift length, including using a cyclic drift cell, has been shown previously, however, comes at the cost of sensitivity, which will be hugely detrimental to IMS's ability to deal with biological matrices ${ }^{81}$ Nevertheless, these technologies are still being explored. In this context, it is interesting to note a promising recent approach termed 'Structures for Lossless Ion Manipulations (SLIM)-IMS' that has been developed to have long serpentine path lengths (13 m) which have markedly improved resolution without previously observed large losses in sensitivity. ${ }^{82}$ More recently, SLIM serpentine ultra-long path with extended routing (SUPER) IM-MS with a $112.5 \mathrm{~m}$ pathlength allowed the trapping of an increased amount of ions (2-3 order of magnitude) compared to conventional approaches and the much easier separation of a variety of di- and trisaccharides and a variety of isomeric human milk oligosaccharides. ${ }^{83}$ Recently Ujma et al. also reported a new instrument where ions could be injected into a cyclic IMS separator and separated over multiple cycles. Additionally, ions could be ejected back into a 'prestore' prior to the cyclic IMS separator, collisionally dissociated and re-injected back into the cyclic IMS cell enabling tandem IMS (IMS/IMS) experiments. Using this instrument, they showed excellent separation of anomers and ring open forms of a series of 3 pentasaccharides, including separations of mixtures of these oligosaccharides. ${ }^{84}$

As mentioned previously, CCSs can be derived from IMS measurements and used directly to differentiate structural features. CCSs for specific precursor ions have been stored in databases, such as GlycoMob ${ }^{67}$ and can act as an additional identifying parameter along with MS(/MS), LC retention times etc. ${ }^{68}$ Whilst these databases will be helpful for the identification of glycans formed from well understood pathways for which we have standards, they do not help in the characterization of unknown species. Alternatively performing IMS on product ions generated by dissociation of oligosaccharide precursors has several advantages: there will be fewer potential isomeric combinations for smaller analyte fragments, and consequently the need for standards is dramatically reduced; fragment-based approaches also benefit from the abundance of common glycan motifs, that arise due to economic use of biosynthetic machineries. In a recent example of a fragment-based approach, the Pagel group demonstrated that $\mathrm{N}$-glycans terminating in biologically relevant $\alpha 2,3-\mathrm{Neu} 5 \mathrm{Ac}$ or $\alpha 2,6$-Neu5Ac regioisomers could be differentiated based on the mobility of a terminating $\mathrm{B}_{3}$ - trisaccharide fragment. ${ }^{85}$ Also, $N$-glycoform structural features could be discerned from the CCS of product ion. ${ }^{31-33}$ Both et al. were able to separate and identify terminal hexose and $\mathrm{N}$ acetylhexosamine monosaccharide fragments generated by CID of glycopeptides and free-reducing disaccharides, based on the drift time of the terminal fragment ion. ${ }^{73}$ Crucially, these drift-times were independent of the initial glycoconjugate structure. Subsequently, they determined that in fact these terminal B- and C- monosaccharide product ions retained memory of the anomeric configuration of the glycosidic bond from which it was derived, as well as the stereochemistry of the glycan building block (Figure 4). ${ }^{53}$

These studies suggest an attractive carbohydrate sequencing strategy: multistage fragmentation $\left(\mathrm{MS}^{\mathrm{n}}\right)$ combined with a database of $\alpha / \beta$-monosaccharide fragment CCSs could enable a significant amount of carbohydrate structures to be annotated rapidly. At the moment, there are some limitations that need to be addressed to make such an approach fully viable. Firstly, IMS resolving power on commercial instrumentation is currently incapable of separating mixtures of $\alpha / \beta$ hexose and $\mathrm{N}$-acetylhexosamine product ions, so analysis of branched glycans is more challenging. Secondly, the dissociation energy can affect the arrival time distribution of product ions (with high energies possibly inducing a secondary reaction pathway), which will complicate analysis and identification. Finally, for larger glycan analytes, it is less likely that dissociation will lead to the formation of mono-/di- saccharide terminal fragment ions. Nevertheless, this fragmentbased methodology shows promise as a possible 'sequencing tool', particularly as IMS resolution continues to improve. Increasing knowledge of glycan dissociation pathways can undoubtedly be exploited to facilitate approaches like this one.

\section{Gas-phase IR spectroscopy-MS}

Application of gas-phase IR action spectroscopyMS for carbohydrate analysis is a fairly new field of research. Isolated ions are typically irradiated with a high fluence IR beam to induce multiple photon absorption (IRMPD) overcoming the barrier to dissociation. since IR photons energies are typically lower than the dissociation threshold. The efficiency of light absorption depends on the frequency of the incident light as well as the analytes atomic structure(s). With tunable IR lasers, a spectral range can be scanned and a gasphase vibrational spectrum of an $\mathrm{m} / \mathrm{z}$ selected ion can be constructed. Alternatively, a weak complex between the target analyte and a so-called "messenger" (e.g. He and $\mathrm{H}_{2}$ that do not absorb IR, bind weakly without imparting an effect on the analyte and produces an easily measurable $\mathrm{m} / \mathrm{z}$ shift) can be produced, and the efficiency of its dissociation measured at various IR wavelengths. ${ }^{86,87}$ Care must be taken when interpreting these spectra in case the messenger(s) differentially interact with the target analyte ion in such a way that it perturbs its structure. ${ }^{88}$ Features from experimental vibrational spectra can be compared with theoretical vibrational spectra to derive energy minimized gas-phase simulated structures, and provide insight into potential 3D-conformations. 
One of the pioneering experiments for IR-MS involved plotting the major product ion intensities generated by IRMPD of several mass-selected lithiated diglucosides, that differed by the regiochemistry and anomeric configuration of the glycosidic bond, against the wavelength of FELIX ${ }^{89}$ (scanned between 7-11 $\mu \mathrm{m}$ ). The reproducible 2D plots were unique for each parent, highlighting that the IRMPD was highly sensitive to subtle structural variations in the ionized species (despite their recorded IR spectra being poorly resolved and fairly similar). ${ }^{90} \mathrm{~A}$ similar approach showed that lithiated diglucosides, ${ }^{11}$ and $\alpha$ - and $\beta$ - $O$-methyl-glucopyranosides anomers, ${ }^{92}$ could also be distinguished using more accessible tunable $\mathrm{CO}_{2}$ lasers scanning between 9.2 and 10.8 $\mu \mathrm{m}$. Many of these examples focused on differences between tandem mass spectra rather than IR action spectra. Brown et al. performed IRMPD on all eight unmodified deprotonated D-aldohexoses and again noted differences between tandem mass spectra. ${ }^{93}$ However, a strong absorption in the $1700 \mathrm{~cm}^{-}$ ${ }^{1}$ region was observed for all species. This signal was compared with theoretically generated vibrational spectra and corresponded to a carbonyl signal, highlighting these structures existed as their linear rather than cyclic forms in the gasphase. This observation would have been impossible to directly monitor by MS alone..$^{93}$ Rabus et al. also found ringopen structures for the $\mathrm{C}_{1}$-ion derived from deprotonated lactose. However, they likely form from a ring-opening reaction of the closed-ring structure (whose anomeric configuration was retained) since the barrier for conversion is relatively small $\left(\sim 51 \mathrm{~kJ} \mathrm{~mol}^{-1}\right)$ and is entropically favored. They also propose dissociation pathways, structures and conformations of other fragment ions ( $\mathrm{Z}_{1}$-ion and cross-rings) by combining MS/MS, IR spectroscopy and theoretical simulations. ${ }^{94}$ In comparison, Gray et al. and Schindler et al. found that C-ions generated by CID of lithiated diglucosides were shown to retain the stereochemistry of the parents glycosidic linkage at the $\mathrm{C} 1$ position, irrespective of the regiochemistry of the glycosidic bond or identity of the adjacent reducing residue. ${ }^{53,95}$ These experiments highlight the differences in fragmentation chemistry depending on the polarity and identity of the ion adduct where the anomeric configuration of the glycosidic bond is retained under certain circumstances and lost in others. Contreras et al. performed IRMPD on lithiated $\alpha-/ \beta-O$ methyl- $N$-acetylglucosamine and $\alpha$-/ $\beta$ - $O$-methyl- $N$-acetyl galactosamine and found unique features or peak shifting between the stereoisomers/anomers, enabling all to be differentiated. Energy minimized conformations and corresponding theoretical IR spectra were generated that showed good correlation with experimental measurements, providing a snapshot of potentially viable gas-phase conformations which can be used as evidence to explain observable differences between infrared spectra. ${ }^{96}$ Isobaric sulfated and phosphorylated hexosamines,${ }^{97}$ sulfated hexosamines ${ }^{98}$ and GAG fragments ${ }^{99}$ that differ in the position of sulfation, epimeric $N$ acetylhexosamines, ${ }^{100}$ epimeric hexosamines, ${ }^{101}$ epimeric hexuronic acids ${ }^{102}$, regioisomeric sialic acids ${ }^{103}$ and regio/stereo-isomeric disaccharides ${ }^{95}$ have all been demonstrated to be distinguishable using IR action spectra as unique fingerprints. This is a milestone in our analytical capabilities, as many of these species are inseparable (or poorly separated) by LC, MS(/MS) or conventional IMS. However, many of these spectra display poor resolution despite only consisting of mono-/di-saccharides, possibly masking additional highly diagnostic features. Poor resolution has been proposed to occur due to two factors: the conformational flexibility of gas- phase carbohydrate ions at room temperature, and thermal activation of ions upon sequential absorption of photons during IRMPD. ${ }^{104}$ Consequently, cold-ion IR-MS approaches have recently been applied to glycan analysis. Khanal et al. studied isomeric GAG disaccharide fragments (three chondroitin sulfates and two heparan sulfates) on a "home-built" instrument that combined a DTIMS, a cryogenic ion trap, a time-of-flight mass analyzer and an IR laser. The drift tube could be operated in tandem IMS-IMS mode, where ions with a specific drift time could be selectively gated. Mobility and $\mathrm{m} / \mathrm{z}$, selected ions could be injected into a cryogenic ion trap maintained at $13 \mathrm{~K}$. In this trap, carbohydrate ions would be cooled through collisions with $\mathrm{H}_{2}$ buffer gas and upon cooling, would form weakly bound $\mathrm{H}_{2}$-analyte messenger complexes that could be probed with a tunable IR laser (as discussed previously). ${ }^{105}$ The IR action spectra of these cryogenically cooled fragments were extremely well resolved, providing diagnostic fingerprint spectra for all species. $\triangle \mathrm{UA}-(6 \mathrm{~S}) \mathrm{Glc} N A \mathrm{c}$ displayed two conformations within the arrival time distribution. Using this instrument set up both could be isolated prior to IR irradiation, and separate IR spectra recorded for both conformers. These conformers produced unique spectra, highlighting the wealth of information that can be produced from these hybrid MS experiments. This same strategy was recently applied to isomeric pairs of milk oligosaccharides, LNnT/LNT, 2'-FL/3-FL and LNDFH I/LNDFH II, tagged with a $\mathrm{N}_{2}$ messenger. Many of these are difficult to separate by LC, however, were readily distinguished by their vibrational spectra. ${ }^{106}$ The Rizzo group also performed IMS prior to cryogenic infrared spectroscopy (using $\mathrm{N}_{2}$ as the messenger tag) to separate and selectively probe glycan mixtures. Rather than using DTIMS ( $2 \mathrm{~m}$ length) which displays poorer IMS resolving powers, they make use of TWIMS on a cyclic SLIM (13 m path over 7 cycles) device which displays much greater resolving power. Under these conditions ions whose CCS differed by roughly $0.5 \%$ were resolvable. However, for each cycle they observed an ion loss of up to $3 \%$. Gal $\beta 1,4 \mathrm{Glc}-$ NAc displays a single peak by DTIMS, whereas two are observed using SLIM. It was postulated that these two species are mutorotamer isomers Gal $\beta 1,4 \mathrm{Glc} N A c \alpha$ and Gal $\beta 1,4 \mathrm{Glc}-$ $N A c \beta$, primarily as every glycan they studied displayed two features in the SLIM IMS spectra. These could be separately probed and generated unique IR spectra. Mixtures of isomeric disaccharides and tetrasaccharides were separable by their SLIM device that could then be interrogated by IR. ${ }^{107} \mathrm{Re}-$ cently they also showed by combined selective ${ }^{18} \mathrm{O}$-labelling of the C1-OH group, cryogenic IR-IR double resonance spectroscopy and quantum mechanical computations that for protonated glucosamine three conformers were potentially present chair ${ }^{1} C_{4} \alpha$-anomer, chair ${ }^{4} C_{1} \alpha$-anomer and chair ${ }^{4} C_{1} \beta$ anomer. The $\alpha-/ \beta$ - ratio of these anomers was found to be $\sim 1.8: 1$ close to the solution-phase measurements of $1.7: 1$ (NMR and polarimetry). These measurements suggest the barrier to mutarotation is too high in the gas-phase. ${ }^{108}$ Finally, Mucha et al. employed a different approach avoiding the requirement of a messenger. ${ }^{109}$ Their approach required doping of ions into helium droplets consisting of an average size of $\sim 10^{5}$ atoms cooling the ions to $0.37 \mathrm{~K}$. Irradiation with a high energy IR laser and absorption of multiple resonant photons caused the ion to be ejected from the droplet in a mechanism yet to be defined. The ejection yield, rather than a fragmentation yield, was measured as a function of IR wavelength to generate action IR spectra. This facilitated differentiation of protonated isomeric mono- and di- saccharides, modified at the reducing terminal with an aminopentyl linker, providing 
remarkable resolution and informational content in the IR space (Figure 5). Underivatized isomeric biologically relevant milk oligosaccharides LNnT and LNT and blood group antigens $\mathrm{Le}^{\mathrm{b}}$ and $\mathrm{Le}^{\mathrm{y}}$ could be readily identified by unique features within their spectra.

Current IR-MS approaches typically do not fit into the timeline of on-line LC, since it takes a long time to scan through the IR region and enough ions must be accumulated at each scan point to record reliable representative action IR spectra. However, the first example of on-line HPLC-MS IRMPD was recently published for mono-/di-saccharide anomers, where they significantly reduced the flow rate (from 400 to $100 \mu \mathrm{L} / \mathrm{min}$ ) to facilitate acquisition of IRMPD spectra. Acquisition times were also reduced from $\sim 10 \mathrm{~min}$ to $\sim 6 \mathrm{~min} .{ }^{10}$

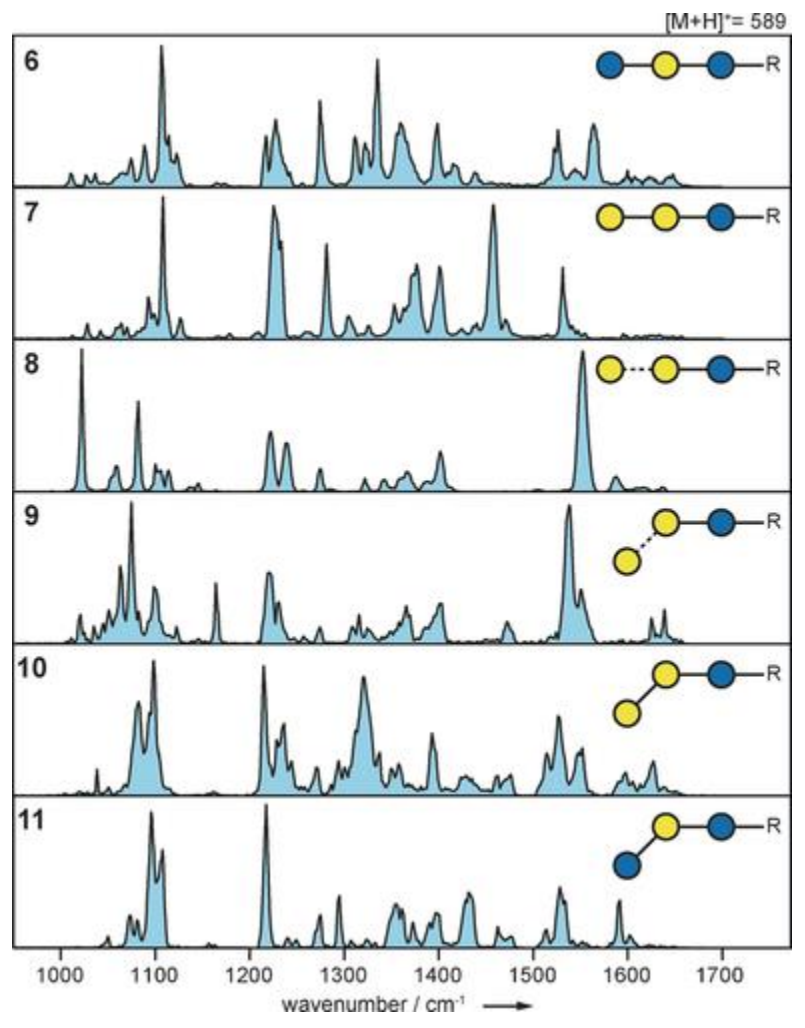

Figure 5. Gas-phase IR spectra associated with a series of isomeric synthetic trisaccharides that differ only by regiochemistry, anomeric configuration or monomer composition. $\mathrm{R}$ corresponds to an aminopentyl moiety. Structures are depicted using SNFG nomenclature ${ }^{8}$ where solid and dashed lines correspond to $\beta$ - and $\alpha$ - configuration respectively and the angle of the connector defines regiochemistry (in this example horizontal lines are linked at the 4- position and the angled the 3-position). Reproduced with permission from publisher. ${ }^{109}$

\section{NMR spectroscopy}

Like any small organic molecule, nucleic acid or protein, carbohydrates are readily detected by solution-state ${ }^{1} \mathrm{H}$ NMR spectroscopy due to the very high natural abundance $(99.985 \%)$ and high frequency of the nucleus. NMR spectroscopy has the advantage over MS that each NMR active nucleus in a molecule gives rise to a resonance, with a characteristic chemical shift being dependent on the structure of the molecule. Elucidation of the complete primary structure of a glycan molecule can be carried out by NMR spectroscopy, in particular, if other NMR active nuclei such as ${ }^{13} \mathrm{C},{ }^{15} \mathrm{~N}$ and/or ${ }^{31} \mathrm{P}$ are utilized, since there exists a plethora of multidimensional techniques to unravel their connectivity. For determination of the absolute configuration of sugar residues, as well as identification of the sugar per se, 2D NMR of diastereomeric compounds obtained by derivatization with optically active 2-butanol, also as mixtures of different sugars, is readily performed. ${ }^{111}$

The general limitation of NMR spectroscopy is that it is insensitive compared to MS and in many cases mg amounts of material are used for NMR-based structural analysis. However, sub-mg quantities of oligosaccharides of unknown structure have been elucidated where their ${ }^{1} \mathrm{H}$ and ${ }^{13} \mathrm{C}$ resonances were assigned using standard equipment with cryogenically cooled NMR probes. ${ }^{112}$ Glycans are also present in what is referred to as natural products, e.g., components of saponins which carry one or more sugars in their structure and an aglycone entity. In natural product chemistry the amount of material may be highly limited and specialized NMR microprobes $(5 \mu \mathrm{L}$ of solvent) are commonly used. It should thus be possible to analyze nanomole amounts, with presentday dedicated cryogenically cooled NMR probes. ${ }^{113}$ The capabilities of NMR spectroscopy in addition to the application of cryogenically cooled NMR probes, will be improved by developing linear prediction techniques, non-uniform sampling and ${ }^{1} \mathrm{H}$-decoupling of ${ }^{1} \mathrm{H}$-detected spectra, i.e., pure shift techniques.

Even if the sensitivity becomes sufficient to detect ${ }^{1} \mathrm{H}$ NMR resonances, glycan structural elucidation may still be hampered due to lack of ${ }^{13} \mathrm{C}$ and ${ }^{15} \mathrm{~N}$ spectral information, since the natural abundance of these nuclei is $\sim 1 \%$ and $<1 \%$, respectively; ${ }^{31} \mathrm{P}$ on the other hand has a natural abundance of $100 \%$, so when present, does not lead to any major sensitivity limitation. The remedy for the low natural abundance for ${ }^{13} \mathrm{C}$ and ${ }^{15} \mathrm{~N}$ is to use isotopically enriched samples, in particular, uniform ${ }^{13} \mathrm{C},{ }^{15} \mathrm{~N}$ enrichment for which optimized NMR techniques have been developed and demonstrated for resonance assignment of sugars and sequence establishment between residues for both oligo- and polysaccharides (Figure 6). ${ }^{114}$ Notably, it is possible to carry out $3 \mathrm{D}{ }^{1} \mathrm{H},{ }^{13} \mathrm{C},{ }^{15} \mathrm{~N}$ NMR experiments where the carbon nuclei are ${ }^{13} \mathrm{C}$-enriched in the polysaccharide material but the ${ }^{15} \mathrm{~N}$ nuclei are still at natural abundance of only $0.37 \% .^{114}$

In contrast to nucleic acid and proteins, the spectral dispersion of carbohydrates is still limited with most ${ }^{1} \mathrm{H}$ NMR signals resonating within $\sim 1 \mathrm{ppm}$ and only a few resonances being observed outside of the bulk spectral region, viz., on the one hand those from anomeric protons, and on the other, those from deoxy-functions such as methyl groups of 6-deoxy-sugars. The resonance assignment process may thus be cumbersome, but will likely be aided by NMR chemical shift prediction tools such as GODDESS ${ }^{115}$ or CASPER. ${ }^{116}$ Using the latter, structural elucidation of an oligo- or polysaccharide can be performed solely by NMR without any resonance assignments provided by the user, i.e., only unassigned NMR spectra are supplied. The capability of predicting NMR chemical shifts accurately and rapidly is also highly beneficial when NMR resonance assignments of unknown structures are carried out manually, and for confirmation of oligoand polysaccharides made by synthetic chemical or enzymatic approaches where a linker or spacer entity is often attached at the reducing end of the saccharide. 
Devoid of any information to complement structural determination of an oligo- or polysaccharide, NMR identification amounts to a humongous task since there are well over a 100 different monosaccharides described to date. ${ }^{117}$ However, if any information on sugar components by other chemical analyses or bioinformatics-including their absolute configuration, anomeric configuration, linkage position as well as substituents - can be supplied as input to the NMR-based structural elucidation, the task becomes manageable as the number of permutations are significantly reduced. Thus, further developing and streamlining this approach ${ }^{118}$ is judged to be highly beneficial to the structural glycochemistry and glycobiology research fields.
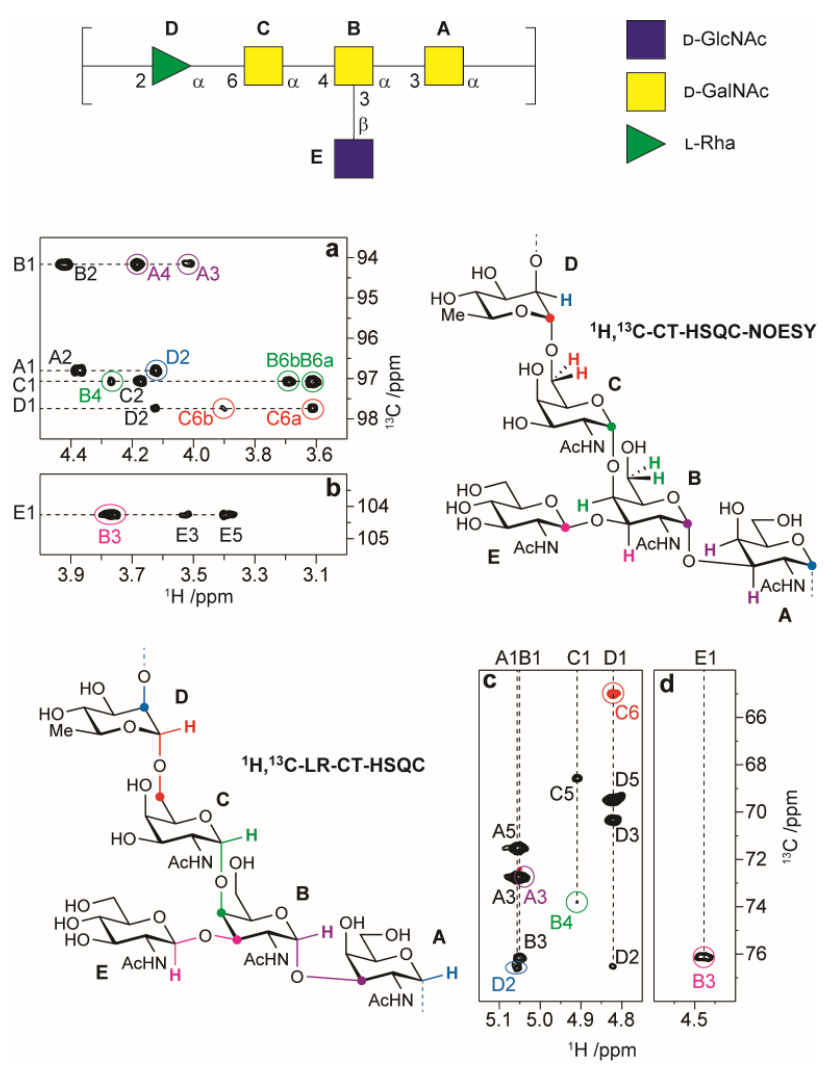

Figure 6. Sequence determination in polysaccharides by NMR. The structure of the repeating unit of the $O$-antigen polysaccharide of E. coli O142 is shown in CFG (Consortium for Functional Glycomics) notation on the top of the figure. Selected regions of the HC-CT-HSQC-NOESY $(2 \mathrm{~T}=44 \mathrm{~ms}, \tau \mathrm{m}=100 \mathrm{~ms})(\mathrm{a}-\mathrm{b})$ and long-range HC-CT-HSQC ( $2 \mathrm{~T}=22 \mathrm{~ms}$ and optimized for $\mathrm{nJCH}$ $=20 \mathrm{~Hz})(\mathrm{c}-\mathrm{d})$ spectra of the ${ }^{13} \mathrm{C}$-enriched $O$-antigen polysaccharide of $\mathrm{E}$. coli $\mathrm{O} 142$, showing intra- and inter-residue correlations from anomeric atoms (the latter are highlighted by colored ovals). The same color nomenclature is used to illustrate the respective inter-residue correlations in the structures located on the right or left side of the respective spectra. Reproduced with permission from publisher. ${ }^{114}$

Computational aspects: informatics, databases and modelling

As carbohydrate analytical approaches (as well as sample preparation) improve their throughput and become hybridized with complimentary instrumentation, the sheer amount of data will rapidly increase. For example, a single tandem mass spectrum of a glycan precursor ion will produce multiple different fragments; within a given MS scan multiple glycan precursors could be selected for dissociation; and if the sample has undergone HPLC separation, there will be thousands of MS(/MS) spectra. This complexity could increase by more than a magnitude when each MS measurement is hyphenated to IMS or gas-phase IR spectroscopy for the precursors/product ions. As a result, manual interpretation for these larger datasets becomes very challenging. Therefore, suitable informatics and databases are (and will continue to be) crucial for determining the most probable structure of a glycan analyte. A number of diverse informatics tools have been developed that facilitate the interpretation of (U/)HPLC, MS, MSMS, $\mathrm{MS}^{\mathrm{n}}$ and NMR data from a range of different carbohydrate classes. Some of these that specifically focus on structure identification, are listed in Table S1 (supporting information). The LC tools generally assign GU values to separated labelled glycans and compare them to database values. $^{24,119}$ Some of these are also integrated with expected GU shifts upon actions of specific exoglycosidases, providing additional indirect structural information. ${ }^{120}$ Given that this is a very new field, there are currently no gold-standards yet for glycan bioinformatics and the field is still continually evolving. ${ }^{121}$ Many of these tools (both LC and MS) specialize for $\mathrm{N}$-linked glycan or glycopeptide analysis. Some of these bioinformatic tools merely match experimental data points to standard datasets whose structures are known. ${ }^{24,60,119,120,122-}$ ${ }^{124}$ Alternatively, knowledge of $N$-glycan biosynthetic pathways also has allowed for theoretical $N$-glycan/glycopeptide structure libraries to be built, whose theoretical MS and MS/MS spectra can be used to help identify experimental MS and MS/MS data. ${ }^{125}$ The presence of glycans/glycoconjugates is often facilitated by looking for monosaccharide oxonium ions ${ }^{126}$, diagnostic $\mathrm{m} / \mathrm{z}$, shifts corresponding to neutral losses of glycans ${ }^{127}$ and/or identifying the presence of conserved core structures. MS/MS $N$-glycan/glycopeptide approaches can build up a topological tree from $\mathrm{m} / \mathrm{z}$ shifts from this core structure constricted by biosynthetic routes. ${ }^{127,} 128$ However, these approaches are disadvantageous when attempting to discern the structures of unknown glycans. Other algorithms are more complex and seek to de novo characterize glycan structures such as GlycoDeNovo, Glyco-Peakfinder and Branch-and-bound. ${ }^{59,129,130}$ These tools are typically restrictive to a certain class of glycans facilitating analysis time and reducing the number of candidate structures. ${ }^{127}$ Many tools however merely provide information of the glycan composition and provide no topological information. ${ }^{131-135}$

There have been multiple databases for a range of native and modified carbohydrates including $\mathrm{N}$ - $/ \mathrm{O}$-linked glycans, ${ }^{24,}, 136-139$ bacterial exopolysaccharides (EPS) ${ }^{140}$ and GAGs $^{141,142}$ containing a range of information from the taxonomy/tissue the glycan was found, the glycans retention properties under a specified set of standard conditions and instrumentation and MS(/MS) spectra (also under specified conditions and instrumentation) to name a few. These databases of known compounds continue to be expanded and show iterated improvements as they become defunct and subsequent databases grow from them. A series of carbohydratelinked databases and the information they provide are listed in Table S2 (supporting information). The ability to compare known database standards for retention times (and corresponding $\mathrm{m} / \mathrm{z}$ ) has been a real cornerstone of (U/)HPLC $\mathrm{N}$ glycomics in being able to identify rapidly the presence or absence of certain glycoforms including those from clinical 


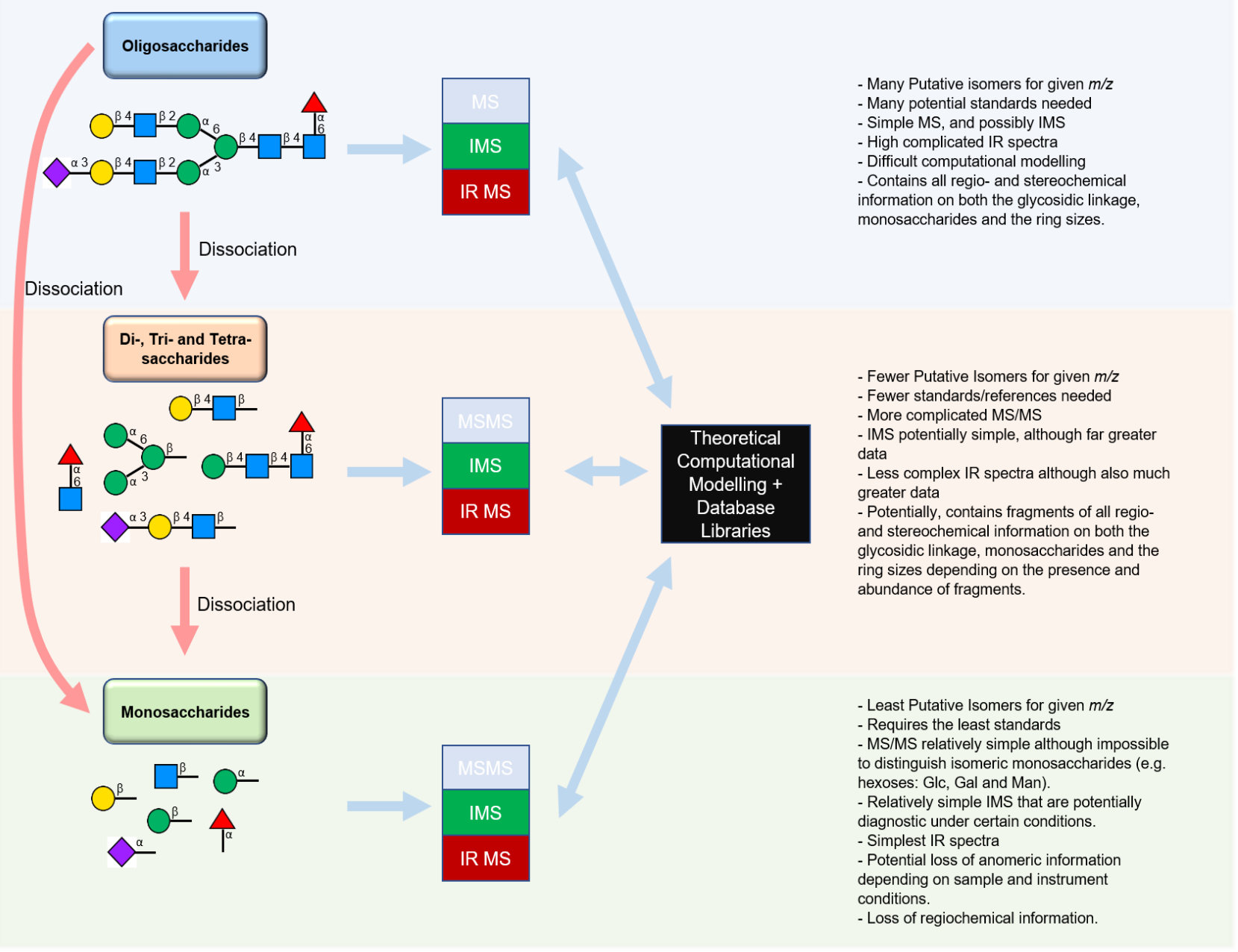

Figure 7. Assessment of current state-of-art of fragment-based approaches, employing the three gas-phase techniques mass spectrometry (MS), ion mobility spectrometry (IMS) and gas-phase IR spectroscopy at various sizes of saccharide after gas-phase dissociation of an oligosaccharide precursor. Oligosaccharide precursors possess the full complement of structural information, however mass spectrometry cannot discern their connectivity, regiochemistry or stereochemistry (although potentially Hex/HexNAc compositions) and IR spectra are very complex. IMS is less complex and measures collisional cross sections that can be compared to standards. Di- to tetra-saccharide fragments can potentially retain all structural information in fragments which can be built back up. Tandem mass spectrometry still does not typically yield stereochemical information, although regiochemistry and connectivity can be discerned. IR spectra of fragments are still very complicated, but simpler than of the precursor and could yield all structural information. IMS spectra may be simple and could be diagnostic compared to a reference library. In combination, exhaustive amounts of data are present which might allow full assignment with high confidence. Finally, monosaccharide fragments can be obtained by extensive fragmentation. Employing just tandem mass spectrometry results in loss of all information associated with connectivity and only provides composition information. IMS allows for the potential differentiation of monomers, even if isobaric, and also has the potential to determine the stereochemistry of the glycosidic bond because of memory effects. IR spectra are less complex than for oligomers and can also be diagnostic for stereochemistry of the glycosidic bond. These experimental approaches can be facilitated by combination with theoretical computation modelling that could generate theoretical IMS CCSs, tandem mass spectra and IR spectra that could evaluate experimental data. Additionally, databases of libraries of spectra could facilitate structural identification. These libraries would need to be exhaustive if they are going to possess information and spectra for all isomeric precursors /oligomer fragment, whereas they become more concise the smaller the fragment size being analyzed.

samples. ${ }^{24,}{ }^{119}, 141$ Comparison of libraries of (LC-)MS/MS spectra for known compounds has been touted as a means of identifying glycans as well. ${ }^{137,141,143,144}$ To the best of our knowledge, only a single database (GlycoMob) containing IMS CCSs has been produced, primarily focusing on precursor ions. ${ }^{67}$ However, it could be hugely beneficial to record CCSs for both the precursor and diagnostic product ions, especially since it would require fewer 'standards' for matching product ion data and they have been shown to be capable of retaining stereochemical information. ${ }^{53,95}$ Currently there are no databases for gas-phase IR spectra where again both precursor and product ion data could be hugely beneficial. This though is primarily due to the technique being relatively new, high specialized and requiring custom non-commercial instrumentation.

It is impracticable to have vast information dense libraries of 'all possible' carbohydrates (including any derivatization) with a full complement of analytical information and consequently they will struggle identifying unknown sequences (in fact they may misidentify unknowns). Therefore, these databases work well for previously identified carbohydrate structures of systems where the biological pathways are 
well understood, characterized and highly conserved. Framework initiatives such as the minimum information required for a glycomics experiment (MIRAGE) that put in place guidelines for reporting results and methodologies for various qualitative and quantitative glycomics experiments will hopefully lead to situations where newly published glycans structures can be readily curated into databases including the analytical methods and sample preparation. ${ }^{121,145,146}$

Finally, computation modelling is potentially hugely impactful in numerous ways for glycan. For example, being able to predict in silico the precise MS/MS fragmentation pathways would greatly facilitate structure assignment as opposed to current approaches that often just generate mass lists from all possible fragments. Similarly, being able to predict the conformational families an oligosaccharide analyte forms is useful for generating theoretical CCSs or theoretical IR spectra. These can be compared to experimental data to improve confidence in assignments and ideally eventually would allow assignments of unusual sugars that have no experimental standards. As in silico CCS calculations and IR spectra also improve, these possibilities become more viable. Computational modeling tools have been very recently reviewed during the submission of this manuscript. ${ }^{147,148}$

\section{Outlook and Concluding remarks}

Unequivocal characterization of all stereochemical information within a given carbohydrate remains an extraordinary challenge for analytical chemists. HPLC or UHPLC strategies to reduce the vast complexity of biological samples prior to more detailed structural interrogation will no doubt still be hugely important especially as techniques head towards automation. It is apparent from research over the past decade that much of the advancement in gaining structural information has revolved around MS analysis and the production of gas-phase ions, as a wide variety of oligosaccharides (and glycan conjugates) can be ionized and manipulated sensitively. MS/MS alone provides incomplete structural information (compositional and sometimes regiochemical), as it is usually 'blind' to stereoisomerism. More elaborate MS/MS, $\mathrm{MS}^{\mathrm{n}}$ and energy-resolved MS/MS approaches that sometimes employ different fragmentation techniques, derivatization or varying adducts have been shown to be capable of distinguishing a variety of isomeric standards. However, these techniques still need to explicitly demonstrate that they can be extended to the detailed structural characterization of more complex precursors. Incorporating IMS gives another dimension of separation to MS analysis and allows assignment sensitive to the three-dimensional structure. Akin to currently exploited chromatographic strategies, identification of glycan precursors from databases of known CCSs, limits its application to unknown glycans. Fortunately, progress in chemical and enzymatic synthesis is beginning to make it possible to prepare large collections of well-defined glycan standards. ${ }^{149}$ Some classes of glycans can be synthesized in an automated fashion, ${ }^{150}$ and chemoenzymatic methods are emerging that can readily provide glycans with highly complex architectures. ${ }^{151}$ Studying the CCS of fragments and comparing these smaller species to previously acquired standards may circumvent this limitation, especially since it has been shown that fragments retain some 'memory' of the precursor ion structure. Moreover, derived tandem mass spectra from multiple types of dissociation strategies are rich in information providing compositionally-specific fingerprints. Current resolution of commercial IMS instrumentation still limits this strategy as it is challenging to get baseline separation of all isomeric mono-/di-saccharides etc. However, the challenge of improving IMS resolving power without much loss in sensitivity is a very active area of investigation.

To overcome some of the limitations of MS and IMMS, the addition of gas-phase IR action spectroscopy has been shown to provide fine structural information, since both precursor and product ions can be studied in most instrument set-ups. Data so far suggest that Vibrational spectra are highly sensitive to structural and conformational variations. Combined with theoretically generated IR spectra (or CCS for IMS measurements) of computationally optimized three-dimensional structures, it may be possible in the future to increase confidence in structural assignments, but considerable development is required since calculations are not straightforward. Cold-ion IR spectroscopy is raising the resolution of these measured vibrational spectra, increasing the likelihood of observing unique identifiable species. This is still a budding area, and it will be very interesting to see how it develops. Currently, its main restrictions are the requirement of complex custom-built instrumentation and FEL facilities for certain experiments. Also, the time required to acquire gasphase vibrational spectra is not currently suitable for highthroughput analyses.

Combinations of these complementary MShyphenated techniques in the gas-phase will likely provide the greatest amount of information and increase confidence in glycan structure assignments (Figure 7). Advanced, informatics tools that can integrate these diverse and informationrich datasets to pull out and annotate significant features, and predict probable structural assignments will be hugely important. ${ }^{152}$

Future developments call for an improvement of the accuracy of NMR chemical shift predictions, where this in part can be made by calculation of the potential of mean force (PMF) surface of oligosaccharides by molecular dynamics (MD) simulations, ${ }^{153}$ using a high-quality force field for carbohydrates, from which a set of conformations are selected and for which their NMR chemical shifts are calculated by quantum chemical methods and weighed according to the corresponding Boltzmann population distribution. In this way, data may be obtained where synthesis or isolation of oligosaccharides is either not possible, or too difficult to carry out. A combined workflow that includes information from techniques such as MS, IR or any other technique that complements the NMR-based structural elucidation, which ultimately may need to be employed if no other technique suffices, as well as bioinformatics integration, will need to be developed and implemented in a web-based application and made available to the glyco-community to drive significant further advances in this area.

\section{Associated Content}

Supporting Information. Two tables containing software and databases that facilitate glycan analysis can be found in the supporting information. This material is available free of charge via the Internet at http://pubs.acs.org.

\section{AUTHOR INFORMATION}

\section{Corresponding Author}

*Sabine.Flitsch@Manchester.ac.uk 


\section{Notes}

The authors declare no competing financial interest.

\section{ACKNOWLEDGMENT}

This work was supported by grants from the U. S. National Institutes of Health (5U01GM116248-02) to N.L.B.P, the Swedish Research Council (no. 2017-03703) to G.W, and ERC (788231-ProgrES-ERC-2017-ADG) EU (CarboMet 737395) BBSRC (IBCarb BB/L013762/1; BB/M027791/1; BB/M02903411; BB/M028836/1) to C.J.G and S.L.F.

\section{REFERENCES}

1. Cummings, R. D.; Pierce, J. M., The Challenge and Promise of Glycomics. Chemistry \& Biology 2014, 21, (1), 1-15.

2. Varki, A., Biological roles of glycans. Glycobiology 2017, 27, (1), 3-49.

3. Knezevic, A.; Polasek, O.; Gornik, O.; Rudan, I.; Campbell, H.; Hayward, C.; Wright, A.; Kolcic, I.; O'Donoghue, N.; Bones, J.; Rudd, P. M.; Lauc, G., Variability, Heritability and Environmental Determinants of Human Plasma N-Glycome. Journal of Proteome Research 2009, 8, (2), 694-701.

4. Knezevic, A.; Gornik, O.; Polasek, O.; Pucic, M.; Redzic, I Novokmet, M.; Rudd, P. M.; Wright, A. F.; Campbell, H.; Rudan, I.; Lauc, G., Effects of aging, body mass index, plasma lipid profiles, and smoking on human plasma N-glycans. Glycobiology 2010, 20, (8), 959969

5. Dalziel, M.; Crispin, M.; Scanlan, C. N.; Zitzmann, N.; Dwek, R. A., Emerging Principles for the Therapeutic Exploitation of Glycosylation. Science 2014, 343, (6166), 37.

6. Doherty, M.; Theodoratou, E.; Walsh, I.; Adamczyk, B.; Stockmann, H.; Agakov, F.; Timofeeva, M.; Trbojevic-Akmacic, I.; Vuckovic, F.; Duffy, F.; McManus, C. A.; Farrington, S. M.; Dunlop, M G.; Perola, M.; Lauc, G.; Campbell, H.; Rudd, P. M., Plasma N-glycans in colorectal cancer risk. Scientific Reports 2018, 8.

7. National Research Council (US) Committee on Assessing the Importance and Impact of Glycomics and Glycosciences, Transforming Glycoscience: A Roadmap for the Future. The National Academies Press: Washington, DC, 2012; p 208

8. Varki, A.; Cummings, R. D.; Aebi, M.; Packer, N. H.; Seeberger, P. H.; Esko, J. D.; Stanley, P.; Hart, G.; Darvill, A.; Kinoshita, T.; Prestegard, J. J.; Schnaar, R. L.; Freeze, H. H.; Marth, J. D.; Bertozzi, C. R.; Etzler, M. E.; Frank, M.; Vliegenthart, J. F. G.; LÃ¹/4tteke, T.; Perez, S.; Bolton, E.; Rudd, P.; Paulson, J.; Kanehisa, M.; Toukach, P.; Aoki-Kinoshita, K. F.; Dell, A.; Narimatsu, H.; York, W.; Taniguchi, N.; Kornfeld, S., Symbol Nomenclature for Graphical Representations of Glycans. Glycobiology 2015, 25, (12), 1323-1324.

9. National Institutes of Health. https://commonfund.nih.gov/Glycoscience (Oct 22nd 2018),

10. Laine, R. A., A Calculation of all possible Oligosaccharide Isomers noth Branched and Linear Yields 1.05 x 1012 Structures for a Reducing Hexasaccharide - The Isomer-Barrier to Development of Single-Method Saccharide Sequencing or Synthesis Systems. Glycobiology 1994, 4, (6), 759-767.

11. Royle, L.; Dwek, R. A.; Rudd, P. M., Determining the Structure of Oligosaccharides N- and O-Linked to Glycoproteins. Current Protocols in Protein Science 2006, 43, (1), 12.6.1-12.6.45.

12. Royle, L.; Radcliffe, C. M.; Dwek, R. A.; Rudd, P. M., Detailed Structural Analysis of N-Glycans Released From Glycoproteins in SDS-PAGE Gel Bands Using HPLC Combined With Exoglycosidase Array Digestions. In Glycobiology Protocols, Brockhausen, I., Ed. Humana Press: Totowa, NJ, 2007; pp 125-143.

13. Royle, L.; Campbell, M. P.; Radcliffe, C. M.; White, D. M.; Harvey, D. J.; Abrahams, J. L.; Kim, Y. G.; Henry, G. W.; Shadick, N. A.; Weinblatt, M. E.; Lee, D. M.; Rudd, P. M.; Dwek, R. A., HPLCbased analysis of serum $\mathrm{N}$-glycans on a 96 -well plate platform with dedicated database software. Analytical Biochemistry 2008, 376, (1), 1-12. 14. Reiding, K. R.; Blank, D.; Kuijper, D. M.; Deelder, A. M Wuhrer, M., High-Throughput Profiling of Protein N-Glycosylation by MALDI-TOF-MS Employing Linkage-Specific Sialic Acid Esterification. Analytical Chemistry 2014, 86, (12), 5784-5793.
15. Shubhakar, A.; Reiding, K. R.; Gardner, R. A.; Spencer, D. I R.; Fernandes, D. L.; Wuhrer, M., High-Throughput Analysis and Automation for Glycomics Studies. Chromatographia 2015, 78, (5-6), 321333

16. Schäffer, C.; Messner, P., Emerging facets of prokaryotic glycosylation. FEMS Microbiology Reviews 2017, 41, (1), 49-91.

17. Veillon, L.; Huang, Y. F.; Peng, W. J.; Dong, X.; Cho, B. G.; Mechref, Y., Characterization of isomeric glycan structures by LCMS/MS. Electrophoresis 2017, 38, (17), 2100-2114.

18. Vreeker, G. C. M.; Wuhrer, M., Reversed-phase separation methods for glycan analysis. Analytical and Bioanalytical Chemistry 2017, 409, (2), 359-378.

19. Nagy, G.; Peng, T. Y.; Pohl, N. L. B., Recent liquid chromatographic approaches and developments for the separation and purification of carbohydrates. Analytical Methods 2017, 9, (24), 3579-3593.

20. Hu, S.; Wong, D. T., Lectin microarray. Proteomics. Clinical applications 2009, 3, (2), 148-154.

21. Gray, C. J.; Weissenborn, M. J.; Eyers, C. E.; Flitsch, S. L., Enzymatic reactions on immobilised substrates. Chemical Society Reviews 2013, 42, (15), 6378-6405.

22. Puvirajesinghe, T. M.; Turnbull, J. E., Glycoarray Technologies: Deciphering Interactions from Proteins to Live Cell Responses. $M i$ croarrays (Basel, Switzerland) 2016, 5, (1), 3.

23. Royle, L.; Radcliffe, C. M.; Dwek, R. A.; Rudd, P. M., Detailed Structural Analysis of N-Glycans Released From Glycoproteins in SDS-PAGE Gel Bands Using HPLC Combined With Exoglycosidase Array Digestions. In Glycobiology Protocols, Brockhausen, I., Ed. Humana Press: Totowa, NJ, 2006; Vol. 347, pp 125-143.

24. Campbell, M. P.; Royle, L.; Radcliffe, C. M.; Dwek, R. A.; Rudd, P. M., GlycoBase and autoGU: tools for HPLC-based glycan analysis. Bioinformatics 2008, 24, (9), 1214-1216.

25. Campbell, M. T.; Chen, D. Z.; Glish, G. L., Distinguishing Linkage Position and Anomeric Configuration of Glucose-Glucose Disaccharides by Water Adduction to Lithiated Molecules. Analytical Chemistry 2018, 90, (3), 2048-2054.

26. Domon, B.; Costello, C. E., A systematic nomenclature for carbohydrate fragmentations in FAB-MS/MS spectra of glycoconjugates. Glycoconjugate Journal 1988, 5, (4), 397-409.

27. Harvey, D. J., Fragmentation of Negative Ions from Carbohydrates: Part 1. Use of Nitrate and Other Anionic Adducts for the Production of Negative Ion Electrospray Spectra from N-linked Carbohydrates. Journal of the American Society for Mass Spectrometry 2005, 16 , (5), 622-630

28. Zhou, S. Y.; Veillon, L.; Dong, X.; Huang, Y. F.; Mechref, Y., Direct comparison of derivatization strategies for LC-MS/MS analysis of N-glycans. Analyst 2017, 142, (23), 4446-4455.

29. Wheeler, S. F.; Domann, P.; Harvey, D. J., Derivatization of sialic acids for stabilization in matrix-assisted laser desorption/ionization mass spectrometry and concomitant differentiation of alpha(2 -> 3)- and alpha(2 -> 6)-isomers. Rapid Communications in Mass Spectrometry 2009, 23, (2), 303-312.

30. Zhou, S. Y.; Huang, Y. F.; Dong, X.; Peng, W. J.; Veillon, L.; Kitagawa, D. A. S.; Aquino, A. J. A.; Mechref, Y., Isomeric Separation of Permethylated Glycans by Porous Graphitic Carbon (PGC)-LCMS/MS at High Temperatures. Analytical Chemistry 2017, 89, (12), 6590-6597.

31. Harvey, D. J.; Watanabe, Y.; Allen, J. D.; Rudd, P.; Pagel, K.; Crispin, M.; Struwe, W. B., Collision Cross Sections and Ion Mobility Separation of Fragment Ions from Complex N-Glycans. Journal of the American Society for Mass Spectrometry 2018, 29, (6), 1250-1261.

32. Harvey, D. J.; Struwe, W. B., Structural Studies of Fucosylated N-Glycans by Ion Mobility Mass Spectrometry and Collision-Induced Fragmentation of Negative Ions. Journal of the American Society for Mass Spectrometry 2018, 29, (6), 1179-1193.

33. Harvey, D. J.; Seabright, G. E.; Vasiljevic, S.; Crispin, M.; Struwe, W. B., Isomer Information from Ion Mobility Separation of High-Mannose Glycan Fragments. Journal of the American Society for Mass Spectrometry 2018, 29, (5), 972-988.

34. Harvey, D. J.; Scarff, C. A.; Edgeworth, M.; Struwe, W. B.; Pagel, K.; Thalassinos, K.; Crispin, M.; Scrivens, J., Travelling-wave ion mobility and negative ion fragmentation of high-mannose $\mathrm{N}$-glycans. Journal of Mass Spectrometry 2016, 51, (3), 219-235.

35. Harvey, D. J.; Scarff, C. A.; Edgeworth, M.; Pagel, K.; Thalassinos, K.; Struwe, W. B.; Crispin, M.; Scrivens, J. H., Travellingwave ion mobility mass spectrometry and negative ion fragmentation of hybrid and complex N-glycans. Journal of Mass Spectrometry 2016, 51, (11), 1064-1079. 

C.; Zaia, J., Comparison of Collisional and Electron-Based Dissociation Modes for Middle-Down Analysis of Multiply Glycosylated Peptides. Journal of the American Society for Mass Spectrometry 2018, 29, (6), 1075-1085.

37. Rabus, J. M.; Abutokaikah, M. T.; Ross, R. T.; Bythell, B. J., Sodium-cationized carbohydrate gas-phase fragmentation chemistry: influence of glycosidic linkage position. Physical Chemistry Chemical Physics 2017, 19, (37), 25643-25652.

$38 . \quad$ Wolff, J. J.; Chi, L. L.; Linhardt, R. J.; Amster, I. J., Distinguishing glucuronic from iduronic acid in glycosaminoglycan tetrasaccharides by using electron detachment dissociation. Analytical Chemistry 2007, 79, (5), 2015-2022.

39. Leach III, F. E.; Riley, N. M.; Westphall, M. S.; Coon, J. J.; Amster, I. J., Negative Electron Transfer Dissociation Sequencing of Increasingly Sulfated Glycosaminoglycan Oligosaccharides on an Orbitrap Mass Spectrometer. Journal of the American Society for Mass Spectrometry 2017, 28, (9), 1844-1854.

40. $\quad$ Agyekum, I.; Zong, C. L.; Boons, G. J.; Amster, I. J., Single Stage Tandem Mass Spectrometry Assignment of the C-5 Uronic Acid Stereochemistry in Heparan Sulfate Tetrasaccharides using Electron Detachment Dissociation. Journal of the American Society for Mass Spectrometry 2017, 28, (9), 1741-1750.

41. Wu, J. D.; Wei, J.; Hogan, J. D.; Chopra, P.; Joshi, A.; Lu, W. G.; Klein, J.; Boons, G. J.; Lin, C.; Zaia, J., Negative Electron Transfer Dissociation Sequencing of 3-O-Sulfation-Containing Heparan Sulfate Oligosaccharides. Journal of the American Society for Mass Spectrometry 2018, 29, (6), 1262-1272.

42. Tang, Y.; Pu, Y.; Gao, J. S.; Hong, P. Y.; Costello, C. E.; Lin, C., De Novo Glycan Sequencing by Electronic Excitation Dissociation and Fixed-Charge Derivatization. Analytical Chemistry 2018, 90, (6), 3793-3801.

43. Adamson, J. T.; Hakansson, K., Electron capture dissociation of oligosaccharides ionized with alkali, alkaline earth, and transition metals. Analytical Chemistry 2007, 79, (7), 2901-2910.

44. Morrison, K. A.; Clowers, B. H., Differential Fragmentation of Mobility-Selected Glycans via Ultraviolet Photodissociation and Ion Mobility-Mass Spectrometry. Journal of the American Society for Mass Spectrometry 2017, 28, (6), 1236-1241.

45. Bayat, P.; Lesage, D.; Cole, R. B., Low-energy collision-induced dissociation (low-energy CID), collision-induced dissociation (CID), and higher energy collision dissociation (HCD) mass spectrometry for structural elucidation of saccharides and clarification of their dissolution mechanism in DMAc/LiCI. Journal of Mass Spectrometry 2018, 53, (8), 705-716.

46. Riggs, D. L.; Hofmann, J.; Hahm, H. S.; Seeberger, P. H.; Pagel, K.; Julian, R. R., Glycan Isomer Identification Using Ultraviolet Photodissociation Initiated Radical Chemistry. Analytical Chemistry 2018, 90, (19), 11581-11588.

47. Li, S.; Zhou, Y.; Xiao, K.; Li, J.; Tian, Z., Selective fragmentation of the N-glycan moiety and protein backbone of ribonuclease B on an Orbitrap Fusion Lumos Tribrid mass spectrometer. Rapid Communications in Mass Spectrometry 2018, 32, (23), 2031-2039.

48. Spina, E.; Sturiale, L.; Romeo, D.; Impallomeni, G.; Garozzo, D.; Waidelich, D.; Glueckmann, M., New fragmentation mechanisms in matrix-assisted laser desorption/ionization time-of-flight/time-of-flight tandem mass spectrometry of carbohydrates. Rapid Communications in Mass Spectrometry 2004, 18, (4), 392-398.

49. Yu, S. Y.; Wu, S. W.; Khoo, K. H., Distinctive characteristics of MALDI-Q/TOF and TOF/TOF tandem mass spectrometry for sequencing of permethylated complex type N-glycans. Glycoconjugate Journal 2006, 23, (5-6), 355-369.

50. Wong, Y. L. E.; Chen, X. F.; Wu, R.; Hung, Y. L. W.; Chan, T. W. D., Structural Characterization of Intact Glycoconjugates by Tandem Mass Spectrometry Using Electron-Induced Dissociation. Analytical Chemistry 2017, 89, (18), 10111-10117.

51. Ashline, D. J.; Lapadula, A. J.; Liu, Y. H.; Lin, M.; Grace, M.; Pramanik, B.; Reinhold, V. N., Carbohydrate structural isomers analyzed by sequential mass spectrometry. Analytical Chemistry 2007, 79, (10), 3830-3842.

52. $\quad$ Prien, J. M.; Ashline, D. J.; Lapadula, A. J.; Zhang, H.; Reinhold, V. N., The High Mannose Glycans from Bovine Ribonuclease B Isomer Characterization by Ion Trap MS. Journal of the American Society for Mass Spectrometry 2009, 20, (4), 539-556.

53. Gray, C. J.; Schindler, B.; Migas, L. G.; Picmanova, M.; Allouche, A. R.; Green, A. P.; Mandal, S.; Motawia, M. S.; SanchezPerez, R.; Bjarnholt, N.; Moller, B. L.; Rijs, A. M.; Barran, P. E.; Com- pagnon, I.; Eyers, C. E.; Flitsch, S. L., Bottom-Up Elucidation of Glycosidic Bond Stereochemistry. Analytical Chemistry 2017, 89, (8), 45404549 .

54. Ashwood, C.; Lin, C. H.; Thaysen-Andersen, M.; Packer, N. $\mathrm{H}$., Discrimination of Isomers of Released N- and O-Glycans Using Diagnostic Product Ions in Negative Ion PGC-LC-ESI-MS/MS. Journal of the American Society for Mass Spectrometry 2018, 29, (6), 1194-1209.

55. Zhu, Y.; Yang, Z. H.; Rodgers, M. T., Influence of Linkage Stereochemistry and Protecting Groups on Glycosidic Bond Stability of Sodium Cationized Glycosyl Phosphates. Journal of the American Society for Mass Spectrometry 2017, 28, (12), 2602-2613.

56. Jovanovic, M.; Tyldesley-Worster, R., Analysis of matrix-assisted laser desorption/ionization quadrupole time-of-flight collision-induced dissociation spectra of simple precursor ions and isobaric oligosaccharide ion mixtures based on product ion intensities and pattern recognition. Rapid Communications in Mass Spectrometry 2017, 31, (10), 873-885.

57. $\quad$ Pett, C.; Nasir, W.; Sihlbom, C.; Olsson, B.-M.; Caixeta, V.; Schorlemer, M.; Zahedi, R. P.; Larson, G. r.; Nilsson, J.; Westerlind, U., Effective Assignment of $\hat{\mathrm{I}} \pm 2,3 / \hat{\mathrm{I}} \pm 2,6-$ Sialic Acid Isomers by LCMS/MS-Based Glycoproteomics. Angewandte Chemie International Edition 2018, 57, (30), 9320-9324.

58. Molina, E. R.; Eizaguirre, A.; Haldys, V.; Urban, D.; Doisneau, G.; Bourdreux, Y.; Beau, J. M.; Salpin, J. Y.; Spezia, R., Characterization of Protonated Model Disaccharides from Tandem Mass Spectrometry and Chemical Dynamics Simulations. Chemphyschem 2017, 18, (19), 2812-2823.

59. Hong, P. Y.; Sun, H.; Sha, L.; Pu, Y.; Khatri, K.; Yu, X.; Tang, Y.; Lin, C., GlycoDeNovo - an Efficient Algorithm for Accurate de novo Glycan Topology Reconstruction from Tandem Mass Spectra. Journal of the American Society for Mass Spectrometry 2017, 28, (11), 2288-2301.

60. Xiao, K. J.; Wang, Y.; Shen, Y.; Han, Y. Y.; Tian, Z. X., Large-scale identification and visualization of $\mathrm{N}$-glycans with primary structures using GlySeeker. Rapid Communications in Mass Spectrometry 2018, 32, (2), 142-148.

61. Wuhrer, M.; Deelder, A. M.; van der Burgt, Y. E. M., Mass Spectrometric Glycan Rearrangements. Mass Spectrometry Reviews 2011, 30, (4), 664-680.

62. Mucha, E.; Lettow, M.; Marianski, M.; Thomas, D. A. Struwe, W. B.; Harvey, D. J.; Meijer, G.; Seeberger, P. H.; von Helden, G.; Pagel, K., Fucose Migration in Intact Protonated Glycan Ions: A Universal Phenomenon in Mass Spectrometry. Angewandte Chemie-International Edition 2018, 57, (25), 7440-7443.

63. Nagy, G.; Pohl, N. L. B., Complete Hexose Isomer Identification with Mass Spectrometry. Journal of the American Society for Mass Spectrometry 2015, 26, (4), 677-685.

64. Nagy, G.; Pohl, N. L. B., Monosaccharide Identification as a First Step toward de Novo Carbohydrate Sequencing: Mass Spectrometry Strategy for the Identification and Differentiation of Diastereomeric and Enantiomeric Pentose Isomers. Analytical Chemistry 2015, 87, (8), 4566-4571.

65. Gray, C. J.; Thomas, B.; Upton, R.; Migas, L. G.; Eyers, C. E.; Barran, P. E.; Flitsch, S. L., Applications of ion mobility mass spectrometry for high throughput, high resolution glycan analysis. Biochimica Et Biophysica Acta-General Subjects 2016, 1860, (8), 16881709.

66. Hofmann, J.; Pagel, K., Glycan Analysis by Ion MobilityMass Spectrometry. Angewandte Chemie-International Edition 2017, 56, (29), 8342-8349.

67. $\quad$ Struwe, W. B.; Pagel, K.; Benesch, J. L. P.; Harvey, D. J.; Campbell, M. P., GlycoMob: an ion mobility-mass spectrometry collision cross section database for glycomics. Glycoconjugate Journal 2016, 33, (3), 399-404.

68. Glaskin, R. S.; Khatri, K.; Wang, Q.; Zaia, J.; Costello, C. E., Construction of a Database of Collision Cross Section Values for Glycopeptides, Glycans, and Peptides Determined by IM-MS. Analytical Chemistry 2017, 89, (8), 4452-4460.

$69 . \quad$ Williams, J. P.; Grabenauer, M.; Holland, R. J.; Carpenter, C. J.; Wormald, M. R.; Giles, K.; Harvey, D. J.; Bateman, R. H.; Scrivens, J. H.; Bowers, M. T., Characterization of simple isomeric oligosaccharides and the rapid separation of glycan mixtures by ion mobility mass spectrometry. International Journal of Mass Spectrometry 2010, 298, (13), 119-127.

70. Lanucara, F.; Holman, S. W.; Gray, C. J.; Eyers, C. E., The power of ion mobility-mass spectrometry for structural characterization and the study of conformational dynamics. Nature Chemistry 2014, 6, (4), 281-294. 
71. Hofmann, J.; Hahm, H. S.; Seeberger, P. H.; Pagel, K., Identification of carbohydrate anomers using ion mobility-mass spectrometry. Nature 2015, 526, (7572), 241-244.

72. $\quad$ Li, H. L.; Giles, K.; Bendiak, B.; Kaplan, K.; Siems, W. F.; Hill, H. H., Resolving Structural Isomers of Monosaccharide Methyl Glycosides Using Drift Tube and Traveling Wave Ion Mobility Mass Spectrometry. Analytical Chemistry 2012, 84, (7), 3231-3239.

73. $\quad$ Both, P.; Green, A. P.; Gray, C. J.; Sardzik, R.; Voglmeir, J.; Fontana, C.; Austeri, M.; Rejzek, M.; Richardson, D.; Field, R. A.; Widmalm, G.; Flitsch, S. L.; Eyers, C. E., Discrimination of epimeric glycans and glycopeptides using IM-MS and its potential for carbohydrate sequencing. Nature Chemistry 2014, 6, (1), 65-74.

74. Huang, Y. T.; Dodds, E. D., Discrimination of Isomeric Carbohydrates as the Electron Transfer Products of Group II Cation Adducts by Ion Mobility Spectrometry and Tandem Mass Spectrometry. Analytical Chemistry 2015, 87, (11), 5664-5668.

75. Huang, Y. T.; Dodds, E. D., Ion-neutral collisional cross sections of carbohydrate isomers as divalent cation adducts and their electron transfer products. Analyst 2015, 14, (20), 6912-6921.

76. Huang, Y. T.; Dodds, E. D., Ion Mobility Studies of Carbohydrates as Group I Adducts: Isomer Specific Collisional Cross Section Dependence on Metal Ion Radius. Analytical Chemistry 2013, 85, (20), 9728-9735.

77. Morrison, K. A.; Bendiak, B. K.; Clowers, B. H., Assessment of Dimeric Metal-Glycan Adducts via Isotopic Labeling and Ion Mobility-Mass Spectrometry. Journal of the American Society for Mass Spectrometry 2018, 29, (8), 1638-1649.

78. Dwivedi, P.; Bendiak, B.; Clowers, B. H.; Hill, H. H., Rapid resolution of carbohydrate isomers by electrospray ionization ambient pressure ion mobility spectrometry-time-of-flight mass spectrometry (ESI-APIMS-TOFMS). Journal of the American Society for Mass Spectrometry 2007, 18, (7), 1163-1175.

79. $\quad$ Gaye, M. M.; Nagy, G.; Clemmer, D. E.; Pohl, N. L. B., Multidimensional Analysis of 16 Glucose Isomers by Ion Mobility Spectrometry. Analytical Chemistry 2016, 88, (4), 2335-2344.

80. Li, L.; McKenna, K. R.; Li, Z.; Yadav, M.; Krishnamurthy, R.; Liotta, C. L.; Fernandez, F. M., Rapid resolution of carbohydrate isomers via multi-site derivatization ion mobility-mass spectrometry. Analyst 2018, 143, (4), 949-955.

81. Merenbloom, S. I.; Glaskin, R. S.; Henson, Z. B.; Clemmer, D. E., High-Resolution Ion Cyclotron Mobility Spectrometry. Analytical Chemistry 2009, 81, (4), 1482-1487.

82. Deng, L. L.; Ibrahim, Y. M.; Baker, E. S.; Aly, N. A.; Hamid, A. M.; Zhang, X.; Zheng, X. Y.; Garimella, S. V. B.; Webb, I. K.; Prost, S. A.; Sandoval, J. A.; Norheim, R. V.; Anderson, G. A.; Tolmachev, A. V.; Smith, R. D., Ion Mobility Separations of Isomers based upon Long Path Length Structures for Lossless Ion Manipulations Combined with Mass Spectrometry. Chemistryselect 2016, 1, (10), 2396-2399.

83. Nagy, G.; Attah, I. K.; Garimella, S. V. B.; Tang, K. Q.; Ibrahim, Y. M.; Baker, E. S.; Smith, R. D., Unraveling the isomeric heterogeneity of glycans: ion mobility separations in structures for lossless ion manipulations. Chemical Communications 2018, 54, (83), 11701-11704. 84. Ujma, J.; Ropartz, D.; Giles, K.; Richardson, K.; Langridge, D.; Wildgoose, J.; Green, M.; Pringle, S., Cyclic Ion Mobility Mass Spectrometry Distinguishes Anomers and Open-Ring Forms of Pentasaccharides. Journal of the American Society for Mass Spectrometry 2019, 30, (6), 1028-1037.

85. Hinneburg, H.; Hofmann, J.; Struwe, W. B.; Thader, A.; Altmann, F.; Silva, D. V.; Seeberger, P. H.; Pagel, K.; Kolarich, D., Distinguishing $\mathrm{N}$-acetylneuraminic acid linkage isomers on glycopeptides by ion mobility-mass spectrometry. Chemical Communications 2016, 52, (23), 4381-4384.

86. Polfer, N. C., Infrared multiple photon dissociation spectroscopy of trapped ions. Chemical Society Reviews 2011, 40, (5), 22112221 .

87. Rijs, A. M.; Oomens, J., IR Spectroscopic Techniques to Study Isolated Biomolecules. In Gas-Phase IR Spectroscopy and Structure of Biological Molecules, Rijs, A.; Oomens, J., Eds. Springer, Cham: 2015; Vol. 364, pp 1-42.

88. Masson, A.; Williams, E. R.; Rizzo, T. R., Molecular hydrogen messengers can lead to structural infidelity: A cautionary tale of protonated glycine. Journal of Chemical Physics 2015, 143, (10).

89. Oepts, D.; van der Meer, A. F. G.; van Amersfoort, P. W., The Free-Electron-Laser user facility FELIX. Infrared Physics \& Technology 1995, 36, (1), 297-308.

90. $\quad$ Polfer, N. C.; Valle, J. J.; Moore, D. T.; Oomens, J.; Eyler, J. R.; Bendiak, B., Differentiation of isomers by wavelength-tunable infra- red multiple-photon dissociation-mass spectrometry: Application to glucose-containing disaccharides. Analytical Chemistry 2006, 78, (3), 670 679.

91. Stefan, S. E.; Eyler, J. R., Differentiation of glucose-containing disaccharides by infrared multiple photon dissociation with a tunable $\mathrm{CO} 2$ laser and Fourier transform ion cyclotron resonance mass spectrometry. International Journal of Mass Spectrometry 2010, 297, (1-3), 96101

92. Stefan, S. E.; Eyler, J. R., Differentiation of Methyl-glucopyranoside Anomers by Infrared Multiple Photon Dissociation with a Tunable CO2 Laser. Analytical Chemistry 2009, 81, (3), 1224-1227.

93. Brown, D. J.; Stefan, S. E.; Berden, G.; Steill, J. D.; Oomens, J.; Eyler, J. R.; Bendiak, B., Direct evidence for the ring opening of monosaccharide anions in the gas phase: photodissociation of aldohexoses and aldohexoses derived from disaccharides using variable-wavelength infrared irradiation in the carbonyl stretch region. Carbohydrate Research 2011, 346, (15), 2469-2481.

94. Rabus, J. M.; Simmons, D. R.; Maître, P.; Bythell, B. J., Deprotonated carbohydrate anion fragmentation chemistry: structural evidence from tandem mass spectrometry, infra-red spectroscopy, and theory. Physical Chemistry Chemical Physics 2018, 20, (44), 27897-27909. 95. Schindler, B.; Barnes, L.; Renois, G.; Gray, C.; Chambert, S.; Fort, S.; Flitsch, S.; Loison, C.; Allouche, A. R.; Compagnon, I., Anomeric memory of the glycosidic bond upon fragmentation and its consequences for carbohydrate sequencing. Nature Communications 2017, 8. 96. Contreras, C. S.; Polfer, N. C.; Oomens, J.; Steill, J. D.; Bendiak, B.; Eyler, J. R., On the path to glycan conformer identification: Gas-phase study of the anomers of methyl glycosides of N-acetyl-D-glucosamine and $\mathrm{N}$-acetyl-D-galactosamine. International Journal of Mass Spectrometry 2012, 330, 285-294.

97. Schindler, B.; Joshi, J.; Allouche, A. R.; Simon, D.; Chambert, S.; Brites, V.; Gaigeot, M. P.; Compagnon, I., Distinguishing isobaric phosphated and sulfated carbohydrates by coupling of mass spectrometry with gas phase vibrational spectroscopy. Physical Chemistry Chemical Physics 2014, 16, (40), 22131-22138.

98. $\quad$ Schindler, B.; Barnes, L.; Gray, C. J.; Chambert, S.; Flitsch, S. L.; Oomens, J.; Daniel, R.; Allouche, A. R.; Compagnon, I., IRMPD Spectroscopy Sheds New (Infrared) Light on the Sulfate Pattern of Carbohydrates. Journal of Physical Chemistry A 2017, 121, (10), 2114-2120. 99. Renois-Predelus, G.; Schindler, B.; Compagnon, I., Analysis of Sulfate Patterns in Glycosaminoglycan Oligosaccharides by MSn Coupled to Infrared Ion Spectroscopy: the Case of GalNAc4S and GalNAc6S. Journal of the American Society for Mass Spectrometry 2018, $29,(6), 1242-1249$

100. Tan, Y. L.; Zhao, N.; Liu, J. F.; Li, P. F.; Stedwell, C. N.; Yu, L.; Polfer, N. C., Vibrational Signatures of Isomeric Lithiated N-acetylD-hexosamines by Gas-Phase Infrared Multiple-Photon Dissociation (IRMPD) Spectroscopy. Journal of the American Society for Mass Spectrometry 2017, 28, (3), 539-550.

101. Barnes, L.; Schindler, B.; Chambert, S.; Allouche, A. R. Compagnon, I., Conformational preferences of protonated N-acetylated hexosamines probed by InfraRed Multiple Photon Dissociation (IRMPD) spectroscopy and ab initio calculations. International Journal of Mass Spectrometry 2017, 421, 116-123.

102. Schindler, B.; Renois-Predelus, G.; Bagdadi, N.; Melizi, S.; Barnes, L.; Chambert, S.; Allouche, A. R.; Compagnon, I., MS/IR, a new MS-based hyphenated method for analysis of hexuronic acid epimers in glycosaminoglycans. Glycoconjugate Journal 2017, 34, (3), 421-425.

103. Depraz Depland, A.; Renois-Predelus, G.; Schindler, B.; Compagnon, I., Identification of sialic acid linkage isomers in glycans using coupled InfraRed Multiple Photon Dissociation (IRMPD) spectroscopy and mass spectrometry. International Journal of Mass Spectrometry 2018, 434, 65-69.

104. Oomens, J.; Sartakov, B. G.; Meijer, G.; Von Helden, G., Gas-phase infrared multiple photon dissociation spectroscopy of massselected molecular ions. International Journal of Mass Spectrometry 2006, 254, (1-2), 1-19.

105. Khanal, N.; Masellis, C.; Kamrath, M. Z.; Clemmer, D. E.; Rizzo, T. R., Glycosaminoglycan Analysis by Cryogenic MessengerTagging IR Spectroscopy Combined with IMS-MS. Analytical Chemistry 2017, 89, (14), 7601-7606.

106. Khanal, N.; Masellis, C.; Kamrath, M. Z.; Clemmer, D. E.; Rizzo, T. R., Cryogenic IR spectroscopy combined with ion mobility spectrometry for the analysis of human milk oligosaccharides. Analyst 2018, 143, (8), 1846-1852.

107. Ben Faleh, A.; Warnke, S.; Rizzo, T. R., Combining Ultrahigh-Resolution Ion-Mobility Spectrometry with Cryogenic Infrared 
Spectroscopy for the Analysis of Glycan Mixtures. Analytical Chemistry 2019, 91, (7), 4876-4882.

108. Scutelnic, V.; Rizzo, T. R., Cryogenic Ion Spectroscopy for Identification of Monosaccharide Anomers. The Journal of Physical Chemistry A 2019, 123, (13), 2815-2819.

109. Mucha, E.; Florez, A. I. G.; Marianski, M.; Thomas, D. A.; Hoffmann, W.; Struwe, W. B.; Hahm, H. S.; Gewinner, S.; Schollkopf, W.; Seeberger, P. H.; von Helden, G.; Pagel, K., Glycan Fingerprinting via Cold-Ion Infrared Spectroscopy. Angewandte Chemie-International Edition 2017, 56, (37), 11248-11251.

110. Schindler, B.; Laloy-Borgna, G.; Barnes, L. c.; Allouche, A.R.; Bouju, E.; Dugas, V.; Demesmay, C.; Compagnon, I., Online Separation and Identification of Isomers Using Infrared Multiple Photon Dissociation Ion Spectroscopy Coupled to Liquid Chromatography: Application to the Analysis of Disaccharides Regio-Isomers and Monosaccharide Anomers. Analytical Chemistry 2018

111. Lundborg, M.; Fontana, C.; Widmalm, G., Automatic Structure Determination of Regular Polysaccharides Based Solely on NMR Spectroscopy. Biomacromolecules 2011, 12, (11), 3851-3855.

112. Fontana, C.; Conde-Alvarez, R.; Stahle, J.; Holst, O.; Iriarte, M.; Zhao, Y.; Arce-Gorvel, V.; Hanniffy, S.; Gorvel, J. P.; Moriyon, I.; Widmalm, G., Structural Studies of Lipopolysaccharide-defective Mutants from Brucella melitensis Identify a Core Oligosaccharide Critical in Virulence. Journal of Biological Chemistry 2016, 291, (14), 7727 7741 .

113. Dalisay, D. S.; Molinski, T. F., NMR Quantitation of Natural Products at the Nanomole Scale. Journal of Natural Products 2009, 72, (4), 739-744.

114. Fontana, C.; Kovacs, H.; Widmalm, G., NMR structure analysis of uniformly 13C-labeled carbohydrates. Journal of Biomolecular NMR 2014, 59, (2), 95-110.

115. Kapaev, R. R.; Toukach, P. V., Improved Carbohydrate Structure Generalization Scheme for $1 \mathrm{H}$ and 13C NMR Simulations. Analytical Chemistry 2015, 87, (14), 7006-7010.

116. Lundborg, M.; Widmalm, G., Structural Analysis of Glycans by NMR Chemical Shift Prediction. Analytical Chemistry 2011, 83, (5), 1514-1517.

117. Adibekian, A.; Stallforth, P.; Hecht, M. L.; Werz, D. B.; Gagneux, P.; Seeberger, P. H., Comparative bioinformatics analysis of the mammalian and bacterial glycomes. Chemical Science 2011, 2, (2), 337-344.

118. Fontana, C.; Lundborg, M.; Weintraub, A.; Widmalm, G., Rapid structural elucidation of polysaccharides employing predicted functions of glycosyltransferases and NMR data: Application to the Oantigen of Escherichia coli O59. Glycobiology 2014, 24, (5), 450-457. 119. Zhao, S.; Walsh, I.; Abrahams, J. L.; Royle, L.; Nguyen-Khuong, T.; Spencer, D.; Fernandes, D. L.; Packer, N. H.; Rudd, P. M. Campbell, M. P., GlycoStore: a database of retention properties for glycan analysis. Bioinformatics 2018, 34, (18), 3231-3232.

120. Gotz, L.; Abrahams, J. L.; Mariethoz, J.; Rudd, P. M.; Karlsson, N. G.; Packer, N. H.; Campbell, M. P.; Lisacek, F., GlycoDigest: a tool for the targeted use of exoglycosidase digestions in glycan structure determination. Bioinformatics 2014, 30, (21), 3131-3133.

121. Rojas-Macias, M. A.; Mariethoz, J.; Andersson, P.; Jin, C.; Venkatakrishnan, V.; Aoki, N. P.; Shinmachi, D.; Ashwood, C.; Madunic, K.; Zhang, T.; Miller, R. L.; Horlacher, O.; Struwe, W. B.; Levander, F.; Kolarich, D.; Rudd, P. M.; Wuhrer, M.; Kettner, C.; Packer, N. H.; Aoki-Kinoshita, K. F.; Lisacek, F.; Karlsson, N. G., e-workflow for recording of glycomic mass spectrometric data in compliance with reporting guidelines. bioRxiv, 401141

122. Morimoto, K.; Nishikaze, T.; Yoshizawa, A. C.; Kajihara, S.; Aoshima, K.; Oda, Y.; Tanaka, K., GlycanAnalysis Plug-in: a database search tool for N-glycan structures using mass spectrometry. Bioinformatics 2015, 31, (13), 2217-2219.

123. Walsh, I.; Nguyen-Khuong, T.; Wongtrakul-Kish, K.; Tay, S. J.; Chew, D.; José, T.; Taron, C. H.; Rudd, P. M., GlycanAnalyzer: software for automated interpretation of $\mathrm{N}$-glycan profiles after exoglycosidase digestions. Bioinformatics 2019, 35, (4), 688-690.

124. Go, E. P.; Rebecchi, K. R.; Dalpathado, D. S.; Bandu, M. L.; Zhang, Y.; Desaire, H., GlycoPep DB: A Tool for Glycopeptide Analysis Using a "Smart Search"• . Analytical Chemistry 2007, 79, (4), 17081713.

125. Ren, J. M.; Rejtar, T.; Li, L.; Karger, B. L., N-Glycan Structure Annotation of Glycopeptides Using a Linearized Glycan Structure Database (GlyDB). Journal of Proteome Research 2007, 6, (8), 31623173 .

126. Pioch, M.; Hoffmann, M.; Pralow, A.; Reichl, U.; Rapp, E., glyXtoolMS: An Open-Source Pipeline for Semiautomated Analysis of
Glycopeptide Mass Spectrometry Data. Analytical Chemistry 2018, 90, (20), 11908-11916

127. Yu, C.-Y.; Mayampurath, A.; Zhu, R.; Zacharias, L.; Song, E.; Wang, L.; Mechref, Y.; Tang, H., Automated Glycan Sequencing from Tandem Mass Spectra of N-Linked Glycopeptides. Analytical Chemistry 2016, 88, (11), 5725-5732.

128. Gao, H. Y., Generation of asparagine-linked glycan structure databases and their use. Journal of the American Society for Mass Spectrometry 2009, 20, (9), 1739-1742.

129. Maass, K.; Ranzinger, R.; Geyer, H.; von der Lieth, C.-W.; Geyer, R., "Glyco-peakfinder" - de novo composition analysis of glycoconjugates. Proteomics 2007, 7, (24), 4435-4444.

130. Peltoniemi, H.; Joenväärä, S.; Renkonen, R., De novo glycan structure search with the CID MS/MS spectra of native N-glycopeptides. Glycobiology 2009, 19, (7), 707-714.

131. Kronewitter, S. R.; De Leoz, M. L. A.; Strum, J. S.; An, H. J.; Dimapasoc, L. M.; Guerrero, A.; Miyamoto, S.; Lebrilla, C. B.; Leiserowitz, G. S., The glycolyzer: Automated glycan annotation software for high performance mass spectrometry and its application to ovarian cancer glycan biomarker discovery. Proteomics 2012, 12, (15-16), 2523 2538 .

132. Goldberg, D.; Sutton-Smith, M.; Paulson, J.; Dell, A., Automatic annotation of matrix-assisted laser desorption/ionization N-glycan spectra. Proteomics 2005, 5, (4), 865-875.

133. An, H. J.; Tillinghast, J. S.; Woodruff, D. L.; Rocke, D. M.; Lebrilla, C. B., A New Computer Program (GlycoX) To Determine Simultaneously the Glycosylation Sites and Oligosaccharide Heterogeneity of Glycoproteins. Journal of Proteome Research 2006, 5, (10), 28002808.

134. Maxwell, E.; Tan, Y.; Tan, Y.; Hu, H.; Benson, G.; Aizikov, K.; Conley, S.; Staples, G. O.; Slysz, G. W.; Smith, R. D.; Zaia, J., GlycReSoft: A Software Package for Automated Recognition of Glycans from LC/MS Data. PLoS One 2012, 7, (9), e45474.

135. Cooper, C. A.; Gasteiger, E.; Packer, N. H., GlycoMod - A software tool for determining glycosylation compositions from mass spectrometric data. Proteomics 2001, 1, (2), 340-349.

136. Wang, J.; Torii, M.; Liu, H.; Hart, G. W.; Hu, Z.-Z., dbOGAP - An Integrated Bioinformatics Resource for Protein O-GlcNAcylation. BMC Bioinformatics 2011, 12, (1), 91.

137. von der Lieth, C.-W.; Freire, A. A.; Blank, D.; Campbell, M. P.; Ceroni, A.; Damerell, D. R.; Dell, A.; Dwek, R. A.; Ernst, B.; Fogh, R.; Frank, M.; Geyer, H.; Geyer, R.; Harrison, M. J.; Henrick, K.; Herget, S.; Hull, W. E.; Ionides, J.; Joshi, H. J.; Kamerling, J. P.; Leeflang, B. R.; Lütteke, T.; Lundborg, M.; Maass, K.; Merry, A.; Ranzinger, R.; Rosen, J.; Royle, L.; Rudd, P. M.; Schloissnig, S.; Stenutz, R.; Vranken, W. F.; Widmalm, G.; Haslam, S. M., EUROCarbDB: An open-access platform for glycoinformatics. Glycobiology 2011, 21, (4), 493-502.

138. Böhm, M.; Bohne-Lang, A.; Frank, M.; Loss, A.; RojasMacias, M. A.; Lütteke, T., Glycosciences.DB: an annotated data collection linking glycomics and proteomics data (2018 update). Nucleic Acids Research 2019, 47, (D1), D1195-D1201.

139. Aoki-Kinoshita, K.; Agravat, S.; Aoki, N. P.; Arpinar, S.; Cummings, R. D.; Fujita, A.; Fujita, N.; Hart, G. M.; Haslam, S. M.; Kawasaki, T.; Matsubara, M.; Moreman, K. W.; Okuda, S.; Pierce, M.; Ranzinger, R.; Shikanai, T.; Shinmachi, D.; Solovieva, E.; Suzuki, Y.; Tsuchiya, S.; Yamada, I.; York, W. S.; Zaia, J.; Narimatsu, H., GlyTouCan 1.0 - The international glycan structure repository. Nucleic Acids Research 2016, 44, (D1), D1237-D1242.

140. Birch, J.; Van Calsteren, M.-R.; Pérez, S.; Svensson, B., The exopolysaccharide properties and structures database: EPS-DB. Application to bacterial exopolysaccharides. Carbohydrate Polymers 2019, 205, $565-570$.

141. Campbell, M. P.; Nguyen-Khuong, T.; Hayes, C. A.; Flowers, S. A.; Alagesan, K.; Kolarich, D.; Packer, N. H.; Karlsson, N. G., Validation of the curation pipeline of UniCarb-DB: Building a global glycan reference MS/MS repository. Biochimica et Biophysica Acta (BBA) Proteins and Proteomics 2014, 1844, (1, Part A), 108-116.

142. Glycan Library (Glycosciences Laboratory - Imperial College London). http://www.imperial.ac.uk/glycosciences/ (June 8th 2019),

143. NIST Glycan Mass Spectral Reference Library. https://chemdata.nist.gov/glycan/about (June 1st 2019),

144. Kameyama, A.; Kikuchi, N.; Nakaya, S.; Ito, H.; Sato, T. Shikanai, T.; Takahashi, Y.; Takahashi, K.; Narimatsu, H., A Strategy for Identification of Oligosaccharide Structures Using Observational Multistage Mass Spectral Library. Analytical Chemistry 2005, 77, (15), 4719-4725.

145. York, W. S.; Agravat, S.; Aoki-Kinoshita, K. F.; McBride, R.; Campbell, M. P.; Costello, C. E.; Dell, A.; Feizi, T.; Haslam, S. M.; 
Karlsson, N.; Khoo, K.-H.; Kolarich, D.; Liu, Y.; Novotny, M.; Packer, N. H.; Paulson, J. C.; Rapp, E.; Ranzinger, R.; Rudd, P. M.; Smith, D. F.; Struwe, W. B.; Tiemeyer, M.; Wells, L.; Zaia, J.; Kettner, C., MIRAGE: The minimum information required for a glycomics experiment. Glycobiology 2014, 24, (5), 402-406.

146. Struwe, W. B.; Agravat, S.; Aoki-Kinoshita, K. F.; Campbell, M. P.; Costello, C. E.; Dell, A.; Ten, F.; Haslam, S. M.; Karlsson, N. G.; Khoo, K.-H.; Kolarich, D.; Liu, Y.; McBride, R.; Novotny, M. V.; Packer, N. H.; Paulson, J. C.; Rapp, E.; Ranzinger, R.; Rudd, P. M.; Smith, D. F.; Tiemeyer, M.; Wells, L.; York, W. S.; Zaia, J.; Kettner, C., The minimum information required for a glycomics experiment (MIRAGE) project: sample preparation guidelines for reliable reporting of glycomics datasets. Glycobiology 2016, 26, (9), 907-910.

147. Mucha, E.; Stuckmann, A.; Marianski, M.; Struwe, W. B.; Meijer, G.; Pagel, K., In-depth structural analysis of glycans in the gas phase. Chemical Science 2019, 10, (5), 1272-1284.

148. Nagarajan, B.; Sankaranarayanan, N. V.; Desai, U. R., Perspective on computational simulations of glycosaminoglycans. Wiley Interdisciplinary Reviews: Computational Molecular Science 2019, 9, (2), e1388.

149. Boltje, T. J.; Buskas, T.; Boons, G.-J., Opportunities and challenges in synthetic oligosaccharide and glycoconjugate research. Nature Chemistry 2009, $1,611$.

150. Seeberger, P. H., The Logic of Automated Glycan Assembly. Accounts of Chemical Research 2015, 48, (5), 1450-1463.

151. Liu, L.; Prudden, A. R.; Capicciotti, C. J.; Bosman, G. P.; Yang, J. Y.; Chapla, D. G.; Moremen, K. W.; Boons, G. J., Streamlining the Chemoenzymatic Synthesis of Complex N-Glycans by a Stop and Go Strategy. Nature Chemistry In Press.

152. Egorova, K. S.; Toukach, P. V., Glycoinformatics: Bridging Isolated Islands in the Sea of Data. Angewandte Chemie International Edition 2018, 57, (46), 14986-14990.

153. Yang, M. J.; d'Ortoli, T. A.; Sawen, E.; Jana, M.; Widmalm, G.; MacKerell, A. D., Delineating the conformational flexibility of trisaccharides from NMR spectroscopy experiments and computer simulations. Physical Chemistry Chemical Physics 2016, 18, (28), 1877618794. 